\title{
A STUDY ON REGIONAL CIRCULAR ECONOMY SYSTEM AND ITS CONSTRUCTION, OPERATION AND SUGGESTION FOR SHANGHAI
}

Di Wu

Michigan Technological University

Follow this and additional works at: https://digitalcommons.mtu.edu/etds

Part of the Economics Commons

Copyright 2014 Di Wu

\section{Recommended Citation}

Wu, Di, "A STUDY ON REGIONAL CIRCULAR ECONOMY SYSTEM AND ITS CONSTRUCTION, OPERATION AND SUGGESTION FOR SHANGHAI", Master's Thesis, Michigan Technological University, 2014.

https://doi.org/10.37099/mtu.dc.etds/751

Follow this and additional works at: https://digitalcommons.mtu.edu/etds

Part of the Economics Commons 


\title{
A STUDY ON REGIONAL CIRCULAR ECONOMY SYSTEM AND ITS CONSTRUCTION, OPERATION AND SUGGESTION FOR SHANGHAI
}

\section{By}

Di Wu

\begin{abstract}
A THESIS
Submitted in partial fulfillment of the requirements for the degree of MASTER OF SCIENCE

In Applied Natural Resource Economic
\end{abstract}

MICHIGAN TECHNOLOGICAL UNIVERSITY

2014 
This thesis has been approved in partial fulfillment of the requirements for the Degree of MASTER OF SCIENCE in Applied Natural Resource Economic

School of Business and Economics

Thesis Advisor: Gary A. Campbell

Committee Member: Howard Qi

Committee Member: Shiliang Wu

School Dean: Gene Klippel 


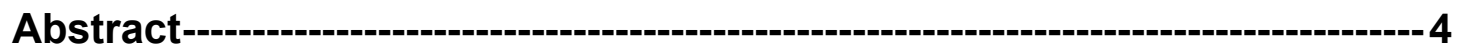

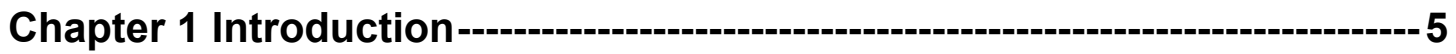

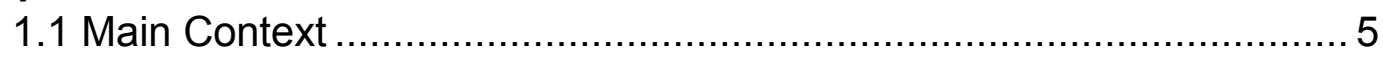

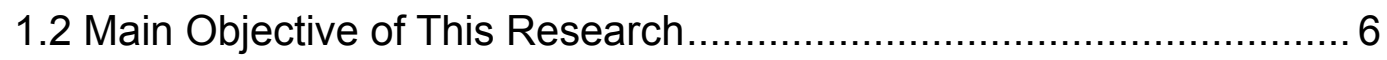

1.3 Research Methods and Innovation .............................................. 7

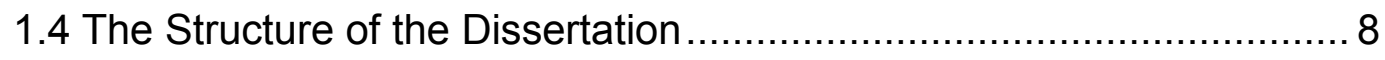

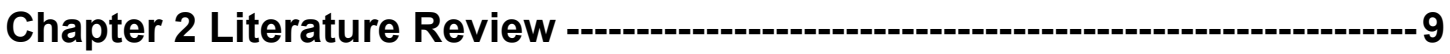

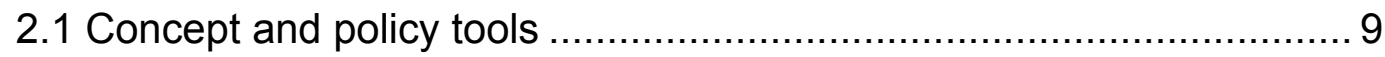

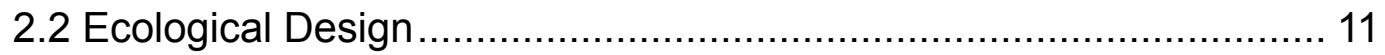

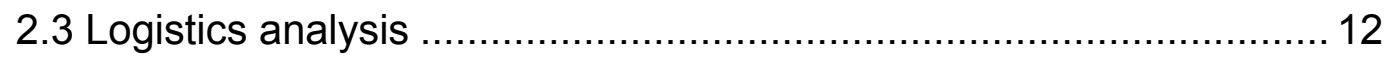

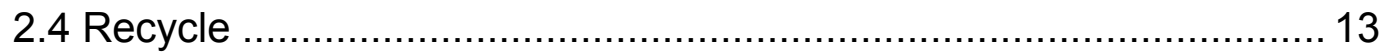

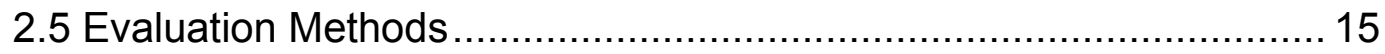

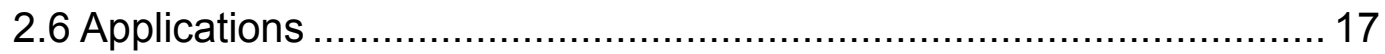

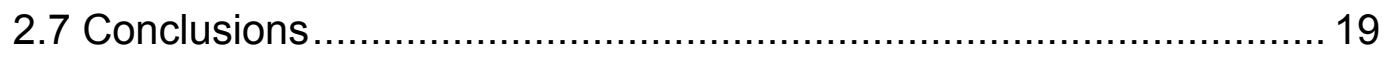

Chapter 3 The basic theory about circular economy research------------ 21

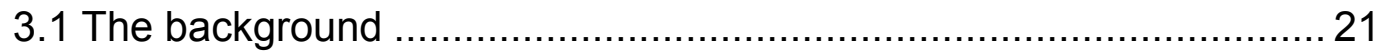

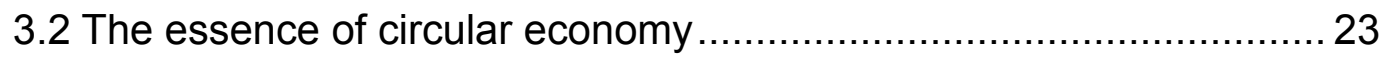

3.3 The theoretical basis of circular economy ...................................... 25

3.4 The industrial classification of circular economy............................ 27

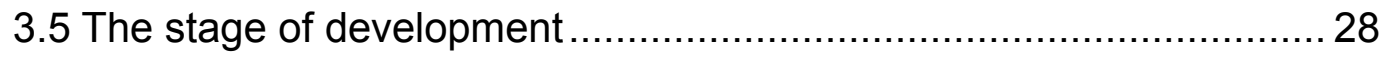

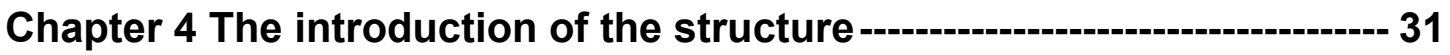

4.1 The structure of the evaluation model ........................................... 31

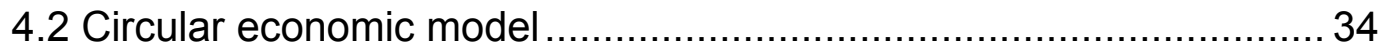

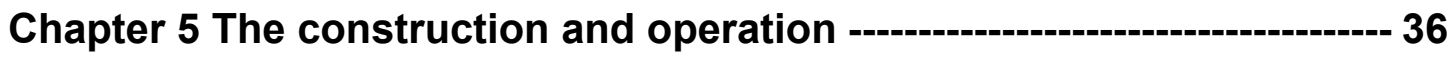

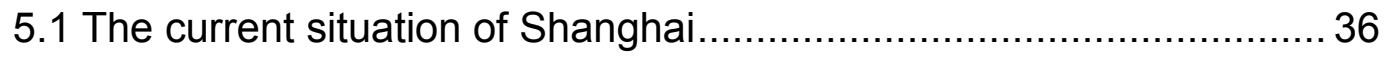

5.2 The construction of the circular economy system.............................. 45

5.3 The structure of the supporting environment .................................5

5.4 The external environment of Shanghai circular economy.................. 55

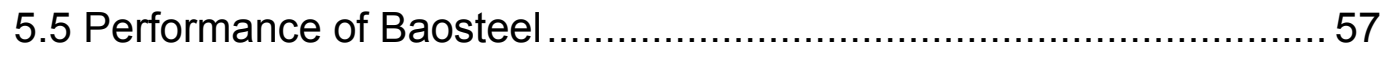

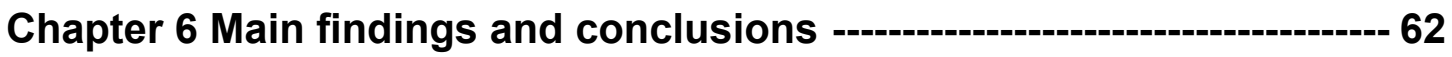

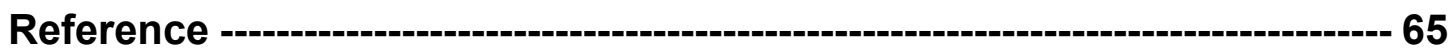




\section{Abstract}

The characteristics of the traditional linear economic model are high consumption, high emission and low efficiency. Economic development is still largely at the expense of the environment and requires a natural resource investment. This can realize rapid economic development but resource depletion and environmental pollution become increasingly serious. In the 1990's a new economic model, circular economics, began to enter our vision. The circular economy maximizes production and minimizes the impact of economic activities on the ecological environment through organizing the activities through the closed-loop feedback cycle of "resources - production - renewable resource". Circular economy is a better way to solve the contradictions between the economic development and resource shortages. Developing circular economy has become the major strategic initiatives to achieving sustainable development in countries all over the world. The evaluation of the development of circular economics is a necessary step for regional circular economy development. Having a quantitative evaluation of circular economy can better monitor and reveal the contradictions and problems in the process of the development of recycling economy.

This thesis will: 1) Create an evaluation model framework and new types of industries and 2) Make an evaluation of the Shanghai circular economy currently to analyze the situation of Shanghai in the development of circular economy. I will then propose suggestions about the structure and development of Shanghai circular economy. 


\section{Chapter 1 Introduction}

\subsection{Main Context}

Human society is now faced with three major issues including environment, resources and population. In the past century humanity has created wealth incomparable to any other time. However humanity has also caused the most serious damage to the ecological environment and natural resources. Environmental pollution and ecological destruction have become the major crisis of the 21st century and one of the main factors restricting the development of the world economy; not to mention harming the health of the people. Industrial production has made a huge contribution to the development of the world economy and the improvement of the quality of human life. When it brought wealth and civilization to humanity, it also brought negative effects. The growth with high input and high consumption caused a big waste of material consumption and pollution. The earth's ecological environment has been damaged at an unprecedented rate. Environmental pollution and ecological destruction have become the major crisis of the 21st century. It has been the common goal of all humanity to maintain ecological balance and to achieve sustainable development. Countries all over the world are now trying to rationalize the use of resources, to minimize the waste generated and to make less pollution in the environment. Due to the meaningful reflection on environmental issues, humanity has begun to study the natural ecosystems which have gone through 4 billion years of evolution.

Circular economy is, essentially, a development model of economy and ecology. Its purpose is to save resources, improve the efficiency of the use of the resource, protect the environment and promote sustained economic development and overall social development, and then from the whole, to achieve the harmony with the human society and the nature. Through simulating the material recycling mode in the natural ecosystems, circular economy will change the one-way material flow model of "resource consumption - product - emissions" to a cycle material flow pattern of "resource consumption - product - renewable resources". Its principle is to reduce, reuse and recycle, which is called $3 R$ principle. 


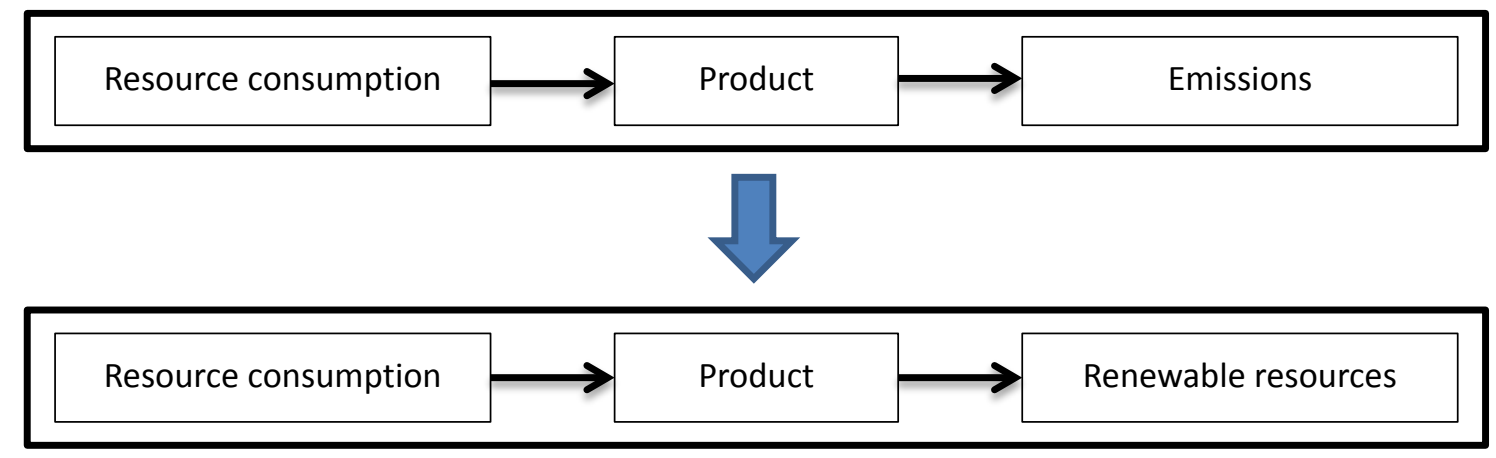

Figure 1-1 Circular economy material flow changes

\subsection{Main Objective of This Research}

In China, the problems caused by solid waste emissions are raising considerable concerns among the general public. In 2002, the total solid waste output from industrial emissions was over 800 million tons, representing an $8 \%$ increase compared with last year. The total accumulated industrial solid waste was nearly 7 billion tons, covering an area of 700 square kilometers, and the accumulated municipal solid waste was almost 650 million tons, covering an area of 600 square kilometers. This garbage not only pollutes the surrounding environment, but also affects the health of people living nearby negatively. China has a huge population which makes the resources comparatively scarce. In addition to this, it has a particularly fragile ecological environment. This means that China's reserved resources and the environmental carrying capacity is unable to withstand the high intensity of resource consumption and environmental pollution that accompanies the traditional form of economic development. The rapid economic development in China has placed a huge amount of pressure on both its environment and resources. If China continues its industrialization process via the traditional measures and only applies the method of end-treatment to protect its environment, a range of environmental problems will emerge including serious pollution, ecological damage and resource depletion. These problems will further undermine the sustained development of the economy and society of mainland China. 
From a long-term perspective, it is better for a society to begin directing development towards a sustainable, circular mode of development and minimize the negative effects of pollution in order to achieve a faster and sound development path. The consumption system in China is still in its formative stages, and the opportunity still exists for China to establish a system that places lower pressure on the country's resources and environment. Perfecting the formation of a production system will contribute to minimizing environmental damage via high-tech and green technologies to develop a circular economy. The current situation of the world makes exploring an effective way to develop a recycling-based economy particularly important, and the practice and exploration of the circular economy on a relatively small scale is an effective means to gain insight that may be applied to the development of a circular economy worldwide. This thesis will therefore attempt to explore the creation and operation of the regional circular economy. One of the earliest regions that have a circular economy will be selected to conduct the experiment, which is Shanghai. A case study will be conducted in Shanghai to examine the nature and effectiveness of the circular economy. Based on the analysis above, the establishment of regional circular economies on a wider scale will be discussed in order to contribute to the understanding of the establishment process of a circular economy for other areas or countries in the world.

\subsection{Research Methods and Innovation}

This thesis will take the Shanghai circular economy as a case study, in which both theoretical and empirical studies of the operation of the regional circular economy will be examined and discussed. The research's background, methodology, and innovations will then be presented. The research methods will combine the study of both economy and ecology and both theoretical deduction and empirical analysis will be applied.

The innovative nature of this research is embodied in the following aspects. Firstly, the framework and pattern for the construction and operation of the regional circular economy developed will be based upon original research and methodology, which cannot be seen elsewhere. Secondly, in 
addition to the general analysis, this research will also analyze the practices of Shanghai in order to establish a unique model for describing the development of the circular economy in Shanghai. Finally, based on the specific problems observed in the development of Shanghai circular economy, some creative solutions will be proposed regarding the construction and operation of the circular economy.

\subsection{The Structure of the Dissertation}

This thesis will be divided into four parts, with the second part covering theoretical background of the issue, the third part covering its application in practice, and the final part concluding the thesis. Chapters Two, Three and Four cover the theoretical backgrounds. Chapter Two will review theory relevant to the study of the circular economy, while Chapter Three will review the background, the nature and the meaning of the circular economy, as well as the current development of this economy. The theoretical basis and the industry classifications of circular economy theory will also be introduced briefly. The framework based on the development of the regional circular economy will be presented in Chapter Four.

The fifth chapter of this thesis will deal with the practical aspect of the circular economy. It will introduce the developmental situation of Shanghai's circular economy, and describe Shanghai in four perspectives, including industry, agriculture, consumers and the resource recycling industry. It will also analyze the policies and measures that have been applied to promote the development of the circular economy in Shanghai.

Based on the above analysis, the thesis will then study the factors influencing the Shanghai circular economy and evaluate its development. Existing problems will be pointed out and some solutions will be proposed. Finally, a conclusion will be made in Chapter Six. 


\section{Chapter 2 Literature Review}

Recycling economy is first proposed by British environmental economists Pearce and Turner in their Economics of natural resources and the environment. But later on, recycling economy did not become an economic model to deal with the relationship between environment and development at the national level.

\subsection{Concept and policy tools}

In the aspect of the economic significance of the circular economy, the American scholar Daly came up with the steady-state economic thought. Heinz Strebel (2004) also did some research about circular economy based on the development process of the concept of sustainable development and the perspective of scarce resources. Heinz Strebel (2004) thought that the circular economy should base on the model of nature and be etched into the ecosphere. There is regular cycle of material and energy. The acquisition, transformation and decomposition of the local material should be achieved by the solar energy. In addition to this, he also made a brief analysis of the possibilities and incentives for the development of the circular economy.

Lydia Illge (2003) applied the economic concepts of market failures, externalities and government failure into the analysis of the circular economy. She analyzed how close the flow of material economy was included in the concept of environment and economy by the method of externalities balance of material, and based on which, Lydia Illge (2003) came up with the basic principles of the environmental policy including waste policy, material policy and integrated product policy. The main context of the thesis has pointed out that circular economy will change the one-way material flow model of "resource consumption - product - emissions" to a cycle material flow pattern of "resource consumption - product - renewable resources" through simulating the material recycling mode in the natural ecosystems.

The main objective of the circular economy is to protect the natural environment and natural 
resources by the closed-loop flow of material. The achievement of circular economy needs the cooperation of all the social subjects including suppliers, manufacturers, retailers, wholesalers, secondary distributors, secondary producers, consumers and so on. Each stakeholder involved must exchange their information. So the information exchanging is considered as the precondition to achieve the closed-loop flow. Blume et al (2004) studied the decision-making management system of circular economy in the cross-company cooperation in his research.

Wedekind et al (2004) studied the cooperation of various participants and the integration of various core capabilities, the connection between service and supply transportation as well as the possibilities of the disposal of the waste. Then they proposed that more and more manufacturers are responsible for the entire life cycle of the product and the creation of an efficient circular economy system needs their efforts. They stressed on the importance of reuse and recycle of the product.

Schwarz et al. (1997) studied the distribution of the industrial cycle network through the production of the companies and the integrated reuse of the waste of the former company. They thought that this integration can help to achieve economic efficiency and material recycling for sustainable development.

Germany should be considered as a good example of circular economy. Goettsching and Lothar (1996) studied the development process of Germany from being an importing country of waste paper in the 1970s to an exporting country of waste paper in the 1990s. They also studied the policies and regulations during that time to promote the circular economy in Germany.

Through learning and imitating, the Government of Shanghai or other parts of China can develop more and more efficiently with circular economy. 


\subsection{Ecological Design}

Recycling is a key link of the circular economy. Whether the recycling can be carried out effectively and smoothly mainly depends on the characteristics of the product recycled. In order to achieve the cycling of the whole society, all the products must be ecological designed to achieve this goal. Therefore, ecological design is an important part of circular economy. And there are a large amount of researches on ecological design. Most of them are in the following three aspects.

The first aspect is about the principles of ecological design and the methods. The scholars Shu Yang et al. (2004) suggested seven principles of ecological design including meeting the needs of the human and the economy, keeping the completeness of the structure and the functions of the natural and management systems, following the example of the applicability of the nature in the human management system, trying to maximize the use of the renewable resources and, etc.

The second aspect of ecological design is about its specific implementation steps. Barbara (1993) conducted a case analysis on IBM, introducing the process of the ecological design of the product including considering which parts or raw materials can be reused or recycled in the initial stage of production, how to recycle the packaging, whether the product will become a hazardous waste in the end of its life, the disposal of the product, how to minimize the waste in the process of production and so on. Barbara (1993) also studied how to make these problems specific, refining and become a normal part of the process of the product development, as well as the establishment of ecological design, the corporate culture and the evaluation of the entire process of ecological design.

The last aspect of ecological design concerns about the analysis of the cost and the benefit. Rosy Wei Chen et al. (1994) analyzed the issues of the industrial ecological design from the view of environment and economy. In order to evaluate the economic efficiency of ecological design, they set up a model to analyze the cost and benefit. Combined with this model, they also proposed the 
rules of ecological design to reduce the cycling cost.

Ecology is of utmost importance to all species including human beings. We, like all other animals depend on this earth for everything: food, water, shelter, etc. Everything on this earth depends on something else but ecology is so dynamic that even the smallest perturbation can cause the collapse of everything. The product emissions will cause extremely serious problems to the whole ecological system such as air, water and land conditions if there is not effective control. These conditions are the basis for the lives of all species.

\subsection{Logistics analysis}

Logistics is an important process of the economic activity. The close-loop flow of the material in the economic system is an important manifestation of the circular economy. In the field of logistics, different scholars have different methods and directions to do research. Considering the coordinated development of the society and economy, the analysis of logistics is mainly about the following aspects, the process of logistics and the measurement of logistics. Lorie A. Wagner (2002) studied the process of the material flow through examining a large number of examples and data. He tracked the process of the material from the mining treating to the final product and the disposal and recycling of the products. He thought that the flow of the material had very important economic, environmental and social impacts at every stage. He also studied the flow and the use of the plastic, metal, paper and industrial minerals and thought that logistics analysis could improve the product design and technology innovation. It also could improve the efficiency of the use of resources and the management of the waste. So the relationship between the economy, resources and ecosystem could be better coordinated. Furthermore, in terms of the measurement of the logistics, material financial accounting (MFA) is used to describe the flow of the materials including the resources, the products, the waste and other emissions. Yuichi Moriguchi (2001) reviewed the main points of the view of MFA and made a discussion about how to connect MFA with other related tools. Bailey et al. (2001) developed the indicators of cycle with the logistics 
model based on the ecology, input and output analysis and pointed out the limitations of the existing measurement methods. They used the matrix of input and output cycle to measure the current ratio of a system or a process of cycle. The comparison of the indicators between the input and output cycle and the matrix of the traditional industrial cycle of a series of hypothetical case shows that this method can be more effective to measure the cycle in the complex logistics systems.

\subsection{Recycle}

Recycling is considered as one of the most important activities for environmental protection. It cannot only reduce the quantity of the waste material but also reduce the consumption of the resources. In a circular economy system, recycling plays an indispensable role. Currently, a large amount of literatures focus on the construction and application of the recycling model.

Recycling is not only a process of production, but also a social activity. Thus, the construction of the model should be able to reflect the interdependence between economic entities (Dobbs 1991). General equilibrium model and input-output model can meet this requirement. In this aspect, Washida (1994), Atri \& Schellberg, (1995), Fullerton \& Kinnaman (1995) and Nakamura (1997) have made some contributions. The preliminary study mainly applied the general equilibrium model and input-output model to develop theory and make empirical analysis about the process of recycling.

Toyoaki Washida (1998) from Japan Kobe University established the economic circular mode on the basis of previous studies. His research was to describe the impossibility conditions of the complete cycle in the consumption of the materials with a simple input and output model which applied the process of recycle and waste joint production. The system proposed by him directly described the flow of the materials in the economic system. The key difference between this system and the value system was that the price of the commodity was measured by the actual 
substance contained in it. What is more, the process of production was expressed according to the physical process of the raw materials converting into a product.

Kleineidam et al. (2000) describes a modeling method of the production chain including recycling. It includes the basic model of the standard process of production connected by market modules. The model analyzed the important characteristics of the nodes in the production chain based on of control theory, including its dynamics, stability, controllability and so on. And they also used an example of paper recycling to study the applicability of the model.

Giuseppe Di Vita (1997) from Italy studied the affection of the process of waste recycling to the open economy and evaluated the possible impacts of waste cycling to the gross national production and the balance of payments with the Keynesian multiplier theory as a theoretical framework. In this way, the policy-makers can better evaluate and compare the pros and cons of the recycling and directly discharging into the environment of the waste. He tried to measure the effects of the waste recycling which might be brought into the important economic aggregates and he also came up with a simulation model to make the process of the resources recycling quantitative.

In recent years, the production and sales of electronic products are growing rapidly and the number of waste product is also growing sustainably and rapidly. Therefore, it is very important to change the waste from land filling to reuse or recycling. And this kind of reverse supply chain requires a systematic and practical framework. Qin Lu et al. (2000) compared the recovery plan and the traditional production plan and gave a theoretical model of the reverse supply chain.

In addition, a number of scholars studied the application and effectiveness of recycling in specific industries and enterprises. For example, Steveis (2002) studied the ecological and economic benefits achieved in the cooperation between the suppliers and the manufacturer in ecological 
design and benchmark and cited the example in the field of product energy consumption, the application of recycled raw materials, recycling and the efficacy in the production. Bhuie et al. (2004) studied the recycling of the electronic products (mainly mobile phones and computers) and analyzed the cost and benefit. Nakajima \& Nina (2000) analyzed how to use the concept of recycling economy in the service industry based on the perspective of the industrial ecology and stressed that the company was selling the service rather than the concept of the products.

\subsection{Evaluation Methods}

Up to now, the research methods about the evaluation of the circular economy mainly include the product life cycle assessment (LCA), material flow analysis (MFA), linear and nonlinear programming techniques, input and output analysis, ecological footprint, the research of the evaluation index system of the cycling economy and so on.

The product life cycle refers to the entire process of the raw material extraction, the production of raw materials, product design and manufacturing, packaging and transportation, selling and consumption, and final waste disposal. The assessment of life cycle involves the entire process of product life which records and evaluates the outputs and the potential environmental impacts of the product system in its life (Nakajima, 2000). In 1993, the international organization for standardization technical committee of environmental management developed the ISO14000 standards for environmental management. LCA was included and defined as a set of methods to collect and measure the environmental impact, the input and output of the material and energy which is directly related to the products or the service in the entire life cycle of the products or the services. Since 1997, the ISO has published the standards of LCA in four phases based on ISO14040 life cycle evaluation principles and framework.

Some researchers used LP (linear programming) technology to evaluate the environmental significance of the different circulation rate in the complicated production and circulation system. 
From example, Hannon \& Brodrick (1982) proposed the LP model of the steel sector in the United States in order to optimize the efficiency of energy and labor in this sector. And Leach, et al. (1997) developed the LP model of the impact of the London paper Life Cycle. Weaver et al. (1995) applied the LP model into the study of circulation problems in the European pulp and paper sector. It is relatively easy to use the linear programming techniques and the static linear model. But it will be a more challenging problem when the optimal control or dynamic optimization is related to the algorithm of the prediction of the time trajectory (Diwekar \& Small, 1998).

Researchers have conducted researches on the applications of the dynamic and non-linear model of the LCA and MFA method. For example, Pistikopoulos et al. (1995) developed a dynamic model. Huppes et al. (1997) applied signal processing method into the evaluation of the characteristics of emissions. Kandelaars \& van den Berg (1997) applieded the control theory model into the environmental policy of the raw materials. Ruth \& Harrington (1998) have developed some dynamic model of the flow of the materials and energy under the condition of the MFA. And Ruth (1995) proposed a nonlinear dynamic model framework for the environmental assessment of the extraction and refining process of the metal resource. Jake McLaren et al (2000) has developed a system modeling of nonlinear dynamic cycle system, and evaluated the energy requirements of an assumed nonlinear dynamic evaluation with different modeling techniques. They also analyzed the difference of the system energy intensity obtained by different types of models and discussed the policy implications of these results. Further researches are still required to create a dynamic nonlinear material circulatory system model with the LCA and MFA method.

In order to evaluate the economic benefits of the cycle system, Masui et al. (2000) from Japan presented a multispectral dynamic macroeconomic model of the flow of the economic activity waste based on the input-output analysis and put it into practical use in Japan. Jaco Huisman et al. (2000) proposed a new method to calculate the loop index named Environmental weights loop method which was based on the environmental impact of the parts of the product. Smith \& 
Raymond L (2004) described a method to hierarchical design and evaluated the producing process of the recycling waste materials.

In addition, researches on the measurement of the circular economy have also been conducted. Wuppertal Institute studied and proposed ecological rucksack. And the University of British Columbia in Canada proposed some eco-efficiency concepts such as ecological footprint (Ecofootprint). Ecological Footprint referred to EF, or ecological occupied space which was proposed by Canadian ecological economist William Rees et al. (1992) and developed by his doctoral student Wackernagel in 1996. It is a method to evaluate the degree of the utilization of the natural resources by human being and the life support and service function to human by the nature. This method is to measure the regional sustainable development by estimating the space area size of the ecological productive which can support the consumption of natural resources of human and the waste produced by assimilating human and compared the ecological carrying capacity of the given area. Another measurement method is useful energy analysis. Useful energy is defined as the useful work of the material flow and energy flow in the balance with the reference environment. It is the latent power of the material changing to be balanced with the reference environment. Useful energy analysis is based on the conservation of mass, the conservation of energy, the first law of thermodynamics and the second law of thermodynamics (Hinderink et al. 1996). This kind of method can determine the location, selection and the loss of the waste and energy so as to achieve the efficient use of energy. Therefore, effective analysis can explain whether or how to reduce inefficiencies in the system in order to achieve high-effectiveness.

These evaluations and measuring calculation processes are extremely complicated, so this thesis will simply create a circular economy system framework and then to explain how the whole system work.

\subsection{Applications}


In terms of the application of circular economy, European scholars Weizsaecker and Bleek proposed the resource productivity multiples theory. From 1990 to 1995, German scholar Professor Weizsaecker came up with four times factor theory. Four times factor theory means that in the economic activity or in the production process we should reduce the inputs of the resource and energy to improve the production efficiency in order to improve the utilization efficiency of resource on the same level of energy to 4 times. In 1994, the German Professor Schmidt Bleek also came up with ten times factor theory. He thought that in 2050 the Earth's population will increase by 1 time and the national gross domestic product will increase by five times. 2 times 5 is 10 , so the impact on the environment will be increased by 10 times. To maintain the existing level of ecology, the efficiency of resource must be improved to reduce the damage to the environment. Therefore, resource and energy efficiency must be increased to 10 times to achieve the sustainable economic and social development. Four times factor theory and ten times factor theory proposed the initial goal and good intentions to solute and remit the environmental issues. This is also an application of the reuse principle of the circular economy, because the linear economy model cannot achieve the goal to increase the efficiency of material resource utilization by times.

In the level of practical application, recycling economy has gradually become a new economic trend in developed countries. Denmark is a pioneer in the practice of circular economy. Karen Eco-Industrial Park takes the power plant, the refinery, the pharmaceutical factory and the gypsum board manufacturing plant as the core and the agriculture, life service industry as auxiliary to achieve the sharing of resources. The usage of the by-products and heat energy can be multiplied. The waste of an enterprise can be used as the raw material of another enterprise, which can help to achieve the goal of zero emissions of pollutants.

The United States has also made some encouraging progress in recycling economy legislation. In 1976, the United States first formulated the Solid Waste Disposal Act. And in 1990, California 
passed the Integrated Waste Management Act. This act requires a $50 \%$ reduction of waste through source reduction and recycling. Interstate alliance consisting of seven states rules that $40-50 \%$ of the newspaper must use the recycled paper. Wisconsin ruled that the plastic containers must use $10-25 \%$ of renewable raw materials. And there are already more than half of the states developing different forms of renewable cycle regulations.

In 2000, Japan held an environmentally congress to adopt and modify a number of environmental laws and regulations which are to promote the formation of circular economy society basic law, to promote the efficient use of resources, food recycling resource recycling promotion law. These regulations have been successively implemented to take the zero emissions as a new business concept and progressively achieve the new industrial structure whose goal is to achieve cleaner production and saving resources.

Recycling economy has not only been driven by the governments of developed country, but also has received a positive response from the business community. Many businesses in the West have used the concept of circular economy at the micro level. They also make some useful exploration and form a good running mode. DuPont chemical company has established an internal circular economy mode and creatively combined the $3 R$ principles of the development of recycling economy with the chemical industry and further developed the $3 R$ manufacturing method to achieve the environmental protection goals of fewer emissions or zero emissions.

\subsection{Conclusions}

In practice, there has been great mass fervor to develop recycling economy in many countries. Many countries all over the world have proposed goals to establish a society with circular economy, design and establish a lot of ecological industrial parks and develop a number of policies and measures. However, the laws and policies to promote the development of circular economy still need to be improved and requires more economic measures. 
Most of the researches from the theoretical point of view focused on the background of the circular economy, the necessity and significance to develop circular economy, and the concepts and principles of developing circular economy, or on the study of the engineering and technologies of circular economy such as clean produce technology, environment sound technology and so on. However, as to the construction of the circular economy industrial system, present researches still stays at three aspects of concepts and framework. The researches on the construction and operation of circular economy system fail to go in-depth. And some researches on circular economy are based on empirical research and almost involve all aspects of circular economy. These studies are deep and specific. However, they are also messy and dispersive, which cannot constitute a complete and unified framework of circular economy theory.

Based the existing evaluation methods, the product life cycle assessment focuses on products and services while the logistics analysis focuses on the analysis and evaluation of the real materials. These two methods are not applicable to a wider range, such as the evaluation of regional circular economy. Ecological footprint method mainly evaluates the impact of the human on the ecosystem through calculating the amount of natural consumption of human for its own survival. But this method cannot describe and evaluate the running state of the circular economic system. The linear and nonlinear programming technology as well as the separate input and output analysis are unable to fully evaluate the operation of the regional circular economy system. Applying circular economy index system can fully measure the level of regional economic benefits, the efficiency of the use of resources and energy, eco-environmental benefits and cycling characteristics to establish an organic link between economic development and ecological environment. Ultimately, the economic development, social progress and environmental protection can all be bettered. However, the circular economy index system is a very complex issue. Although there are some existing researches that have made the initial design, it still needs some practical application, supplement and development. 


\section{Chapter 3 The basic theory about circular economy research}

\subsection{The background}

In the past 100 years, due to the high speed development of nuclear technology, information technology, biological technology, space technology and advanced manufacturing technology, human society and productivity have reached an unprecedented scale. The ability of modern humans to create social wealth and the amount of knowledge that has been acquired and used to implement many significant projects has even been considered miraculous; human society has never been so strong. On the other hand, however, human society has never been faced with such great crises and challenges to its survival as it faces today, such as the explosive growth of the world's population, the rapid rate of consumption of mineral resources and fossil energy, and the increasingly serious water shortage and environmental pollution issues. Tens of billions of tons of industrial waste emissions have led to serious air pollution and the erosion of previously arable land, desertification, the spreading of acid rain, the decrease in the size of the world's forest and cultivatable land, the endangerment of biological diversity, global warming, and the depletion of the ozone layer. All of these problems endanger the health and life of humanity itself, and also greatly restrict the development of the global economy. They even pose a serious threat to the life-supporting ecological system than has taken over four billion years of evolution to form on Earth. Analysis of these environmental problems shows that the crisis in question is caused by human beings; it is the result of the rapid development of industry, agriculture and consumption. Faced with this serious problem, many scholars from the 1960s onward have focused their attention on uncovering solutions. On such solution, Spacecraft Theory, which was put forward by American economist Kenneth Boulding, can be considered as representative of the early theories of the circular economy. Boulding realized during the early stage of the environmental movement how it is necessary to study the related economic processes in order to fully understand the reasons behind environmental problems. He considered the Earth as being like a spacecraft flying through space, constantly consuming its own limited resources in order to remain alive. If human beings continue to exploit its natural resources and damage the environment beyond repair, then 
the Earth would eventually be destroyed, much like a spaceship when the damage it has taken is beyond its capacity to recover from. The economy of the spaceship would therefore require a new circular economy to replace the old consumption-focused form of economy, if it wished to survive far into the future. In June 1972, the United Nations held its Conference on the Human Environment in Stockholm, and passed the declaration of human environment, putting forward powerful slogans including "There is only one earth we can live on" and "The earth is not inherited from the last generation, but borrowed from the hand of offspring". The subsequent 1987 World Environment and Development Committee report, 1992 Declaration of the Environment and Development Conference, 2002 United Nations Sustainable Development Summit meeting in Johannesburg, and the new Declaration and Speech of the Global Environment Fund Convention in Beijing, all continued to stress this concept. Human beings must follow a path of development that not only meets contemporary requirements, but also does not damage the prospects of future generations.

The evolution of the natural ecological system, which has been taking place for more than four billion years, has resulted in a circular process in which all kinds of material are reused in the formation of animals, plants and microorganisms. Natural waste is transformed into the raw materials for growth, then into waste again, then back into life, and this cycle relies only on solar energy as its driving force, a form of energy the density of which is quite low. This situation has however changed due to the past 300 years of humanity's industrial and social development. The scale of mineral resources mining and fossil energy use has expanded significantly, and these materials have been used in a way that leads to constant pollution. The effects of this linear mode of economic development are becoming more and more serious, causing a lack of resources, serious fossil energy shortages and environmental pollution; it is the root cause of the crises faced by the modern industrial system. Sustainable and stable use of these natural resources can only be achieved by following the example of the natural ecological system: establishing a circular economy, where waste products are reused as a vital resource, and developing a system of 
ecological agriculture, ecological industry and ecological consumption. This would also greatly reduce the amount of pollutants escaping into the environment from the production process.

In the 1970s, when the international community began to form movements and organizations dedicated to protecting the environment, the concept of the circular economy was however still considered abstract and distant, and people did not actively seek its implementation. The primary concern at that time of countries across the world was simply with managing and reducing the harm caused by pollutants they produced, with less thought given to recycling. In the 1980s, people began paying more attention to alternative ways for dealing with pollution, but little attention was paid to actually reducing the quantity of pollution resulting from economic production and consumption; environmental protection movements were concerned primarily with the ecological consequences of economic activity, and gave little thought to the economic mechanisms that were actually producing this pollution. In the 1990s, however, the concept of the circular economy began to be developed more clearly.

\subsection{The essence of circular economy}

1. The definition of circular economy

The circular economy is an economy that develops via recycling and reusing the waste. Its goal is to minimize the amount of natural resource consumed by economic production, the amount of pollution discharged into the environment, and the overall ecological damage caused to the environment by the economy. It also can be considered as a means to achieve economic development with low investment, high efficiency and low emissions. Some scholars have contrasted the circular economy with the high consumption, high emissions linear economy that is normally associated with the industrialization process. The circular economy reflects the strategy of sustainable development, whereby natural resources are used in a thoughtful and sustainable manner so as to protect the environment while the economy develops, in order to gradually realize a high efficiency, low cost economy in which pollution emissions are low and the rate of recycling is 
high. The recycling economy can be considered as a kind of ecological economy, requiring that ecological rules instead of just market rules be used to guide the economic activity of human society. Compared with the traditional economy, which is a form of linear economy with a one-way flow of resources, characterized by high production, inefficient resource utilization and high emissions, the circular economy advocates an economic development model that is more in balance with the environment, characterized by low production, efficient resource utilization and low emissions. All the raw materials and energy in a circular economy are used and reused to the maximum degree possible, so as to maximally reduce the influence of economic activities on the natural environment.

There are various different ways in which the circular economy can be described, resulting from the different understandings and perspectives on the issue held by various scholars. These can be categorized into three kinds of viewpoint.

The first kind of viewpoint is from the standpoint of the relationship between humanity and nature. It claims that the economic activities of humans should comply with the laws of the natural ecology and maintain an ecological balance. From this perspective, the essence of the circular economy is to work towards using as few resources as possible and recycling resources.

The second kind of viewpoint is from the standpoint of the technological paradigm of production, and claims that the economy should work towards cleaner methods of production, protecting the environment in the process. It requires the technological paradigm of production to be changed from a uni-directional material flow model (natural resources $->$ production $->$ waste emission) to a closed loop model (resources -> production -> resource), and is characterized by a reduction in resource consumption and an increase in resource reuse. Its essence lies in ecological economics and its core focus is on improving the efficiency with which the ecological environment is used. This viewpoint treats the circular economy as a new kind of mode of production. 
The third kind of viewpoint considers the circular economy as a new form of economy entirely. In this viewpoint, the circular economy is seen as both a new mode of production and a new kind of technological and economic paradigm, one in which the condition of the ecological environment has become a limiting factor on economic growth and fostering a healthy ecological environment can contribute to overall public wealth. Its essence lies in adjusting humanity's production relationships towards the goal of pursuing sustainable development.

2. The characteristics of the circular economy

From the viewpoints of technology and natural ecology, a circular economy has the following characteristics. Firstly, it is technological. The emergence and development of the circular economy is based on advances in science and technology, as only through constant technological progress can human society continue to increase the scale and efficiency at which resources may be recycled. Secondly, it is systematic. The circular economy is a systematic and holistic mode of economic operation that involves every field and every link in the social value production chain. It may take different forms in different parts of the social production process, but these forms cannot reasonably be considered as fundamentally separate. Lastly, the circular economy consists of different levels. The industrial system within the circular economy for instance is divided into three levels: the enterprise level of circulation, the industrial level of circulation and the regional levels of general circulation.

\subsection{The theoretical basis of circular economy}

The advocacy of a new economic development pattern such as the circular economy requires both theoretical and empirical support. Through study of a large quantity of relevant literature, the author has determined that the theoretical foundation of the circular economy can be described in terms of two perspectives: the theory of natural science and economic theory. 
The characteristics of the circular economy are based upon a solid natural science foundation. Firstly, the principles of natural ecology are the source of the concept of the circular economy, as it is derived from analysis of the process of long-term evolution and the formation of the natural ecological system. The natural ecological system has three parts: producers, consumers and disintegrators, and the interaction of these three parts is what forms a mature ecological system. The regional circular economy system also has three parts, and their functionality is equivalent to that of the parts of the natural ecological system. Secondly, the first law of thermodynamics states that the reuse and optimization of resource uses is possible because the materials used in the processes of production and consumption cannot disappear, rather they just change from useful materials into useless waste and then enter the environment as pollution. The differences between useful materials and useless waste are however relative, and through the development of the circular economy not only can the waste produced by the processes of production and consumption can be reduced, but it is also possible for much of the waste generated to be reused. The circular economy hence allows the realization of a system in which production materials can be reused and not wasted.

As the theory of the circular economy is a form of economic theory, it also has foundations in economics. Its first economic foundation is the theory of externalities, which was first proposed by the renowned economist Alfred Marshall at the beginning of the $20^{\text {th }}$ century. Environmental problems are the inevitable result of external diseconomies, and the refinement of the circular economy can produce positive externalities that counter this. If for instance an enterprise implements cleaner production methods, not only does the enterprise itself receive a direct economic benefit, but consumers and society as a whole also receive indirect benefits through the use of green products and the consequent reduction in environmental pollution. The second economic foundation of the circular economy lies in market competition theory. One of the goals of the circular economy is to protect the environment, and while environmental problems have often been excluded from consideration in the market theory of neoclassical economics, there is in fact 
an economy theory, Coase theory, that has shown how voluntary consultation systems and emissions trading systems are economically effective methods for solving environmental problems. Coase theorem describes how, if a market can be constructed for the trade of pollution rights, this market system will determine which organizations are able to engage in pollution in such a way as to reduce overall pollution emissions in the most efficient manner possible. In addition, the price theory of market competition theory has another important role to play in modulating economic activities within the circular economy, as it can prompt enterprises to become engaged in cleaner production processes through adjustment of the price of various resources. The circular economy is still in essence a market economy, it just requires more resource allocation by the government compared with the market economy of the industrial age. The government hence has an important role to play in the effective operation of the circular economy.

\subsection{The industrial classification of circular economy}

This thesis will create an industrial classification system consisting of four industry categories. This system will not only take into account standard industrial factors, but will also combine insights from the science of natural ecology and from circular economy theory.

This first category includes agriculture, forestry, animal husbandry, fishery, and mining.

The second category includes manufacturing, construction, and the production and supply of electric power, gas and water.

The third category includes transportation, warehousing and postal services, information transmission, computer services and software, wholesale and retail trade, the accommodation and catering industry, the financial sector, real estate, lease and business services, scientific research, technical services and the geological prospecting industry, water conservancy, environment and public facilities management, residential services, education, health, and similar services.

The fourth industry is the waste recycling industry. 


\subsection{The stage of development}

The development of the circular economy can be divided into the following stages.

\section{The stage of waste recycling}

As a form of saving, the economic behavior of recycling and reusing waste generated in the process of production and consumption has a long history. In the 1980s, human society entered into the first stage of the development of the circular economy, with environmental protection becoming a widely accepted goal of economic development. The method used for protecting the environment was that of recycling and reusing waste generated by the final stage of the production and consumption process. This stage was led by the government, which actively formulated various environmental laws, regulations and incentive systems for enterprises and residents, encouraging the collection and recycling of waste. The government also provided better legal support to the concept of waste recycling.

Some governments also formulated incentive systems for waste recycling. In Bangkok, for example, the government established a junk bank and encouraged children to collect, classify and bag garbage, and give this garbage to the junk bank. The junk bank would then pay them in the form necessities such as pencils, books and socks as reward. Some governments also took measures to improve the public awareness of environmental issues, with the government of Montreal for example using many different media such as advertising shirts, calendar cards, notebooks and buses to call on the public to actively participate in waste recycling activities.

The focus of this stage was on cultivating public awareness of environmental protection issues, to strengthen the public's understanding and acceptance of the circular economy. In the stage however people only passively recycled waste, which by itself is not sufficient to fundamentally solve the problem of environmental pollution. 
2. The stage of gradually reducing waste emissions

With the unceasing strengthening of the social consciousness of environmental protection, people gradually began to realize that, rather than passively recycling waste after it is produced, it would be better to take active measures to implement clean production, reducing waste emissions by preventing the waste from even being produced. This development stage involves work towards achieving a closed cycle of production that produces zero waste emissions, via methods including green design, the use of ecologically sound processes, and advanced recycling technology. The issue of waste reduction should be given significant attention at each stage in the production process, from the extraction of raw materials to the sale of completed products. At this stage, governments should implement methods to reduce waste emissions such as setting mandatory clean production standards and promoting the use and development of clean production technology.

3. The stage of zero discharge of waste

The primary characteristic of this stage is zero emissions, with government laws and regulations regarding pollution having gradually been perfected. The concept of zero discharge was put forward by the United Nations assembly in 1994. It refers to utilizing clean material circulation technologies and ecological industrial technologies to realize the complete recycling of natural resources used in the production process, to prevent any waste emission to the atmosphere, water or soil of the planet.

In the first two development stages of the circular economy, even if most effective methods of minimizing waste emissions have been realized, the production of waste still cannot be completely avoided. In the third stage however, zero emissions of waste means that it is no longer necessary to distinguish between resources and waste, because the waste of one production process is the resources of another. Material that was in previous stage abandoned as waste will be constantly recycled throughout the circular economy, ultimately achieving the ideal form of a circular 
economy in which zero waste discharge occurs.

\section{The stage of the whole-society cycle}

This is the highest level of development of the circular economy. While the first three stages are mainly focused on the reuse, reduction or recycling of waste, in the fourth stage these $3 R$ principles act as a kind of guiding social principle. Firstly, the use of resources and the production of pollution will be reduced. Secondly, any unavoidable waste from the production process will be reused. In this stage, the whole of society will become part of the cyclical system including production, consumption and recycling. The enterprise will save resources and avoid pollution, the family will actively engage in garbage recycling and green consumption and the government will take measures to maintain and improve the whole circular economic system. 


\section{Chapter 4 The introduction of the structure}

The purpose of this chapter is to establish the evaluation model framework of regional circular economy system, so that we can find out the influence factors of circular economy development based on the evaluation of the current situation of the development of regional circular economy, and put forward general analysis and suggestions in order to improve the regional circular economy system.

\subsection{The structure of the evaluation model}

First, the system can be separated to the following three cycle levels.

1. The small cycle in the enterprise.

That means the circular reuse during the manufacturing including: reuse the loss raw material back to the manufacturing procedure, recycle the emissions from the product back to the manufacturing procedure or other use procedures.

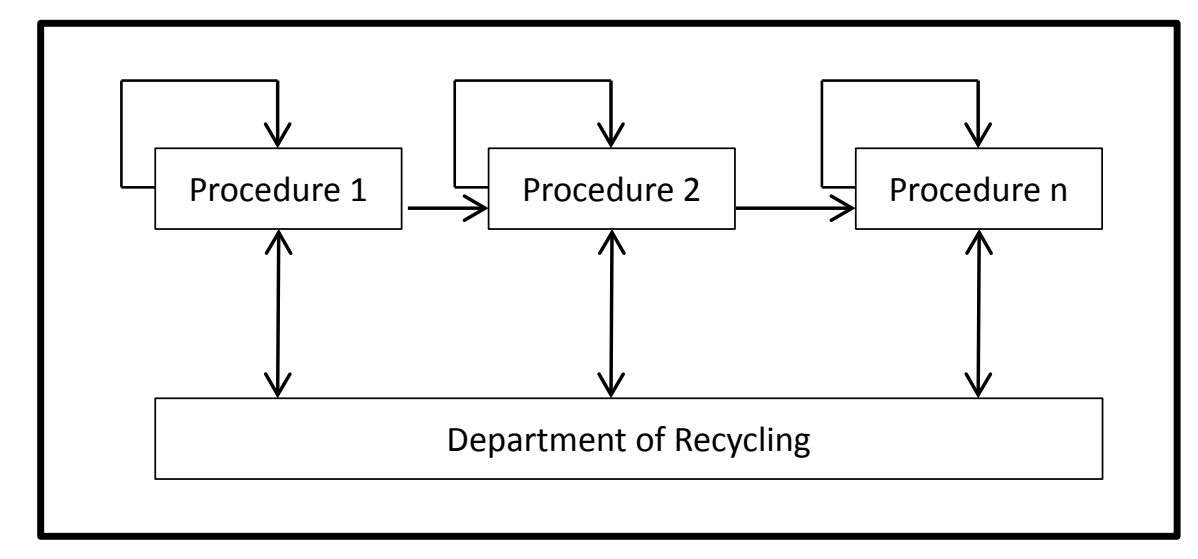

Figure 4-1 Small Cycle 
2. The middle cycle among the industry.

Combining different companies and enterprises together is an effective way to create a system of resource sharing and by-product exchanging. One's emissions like air or water may be another one's material or resource.

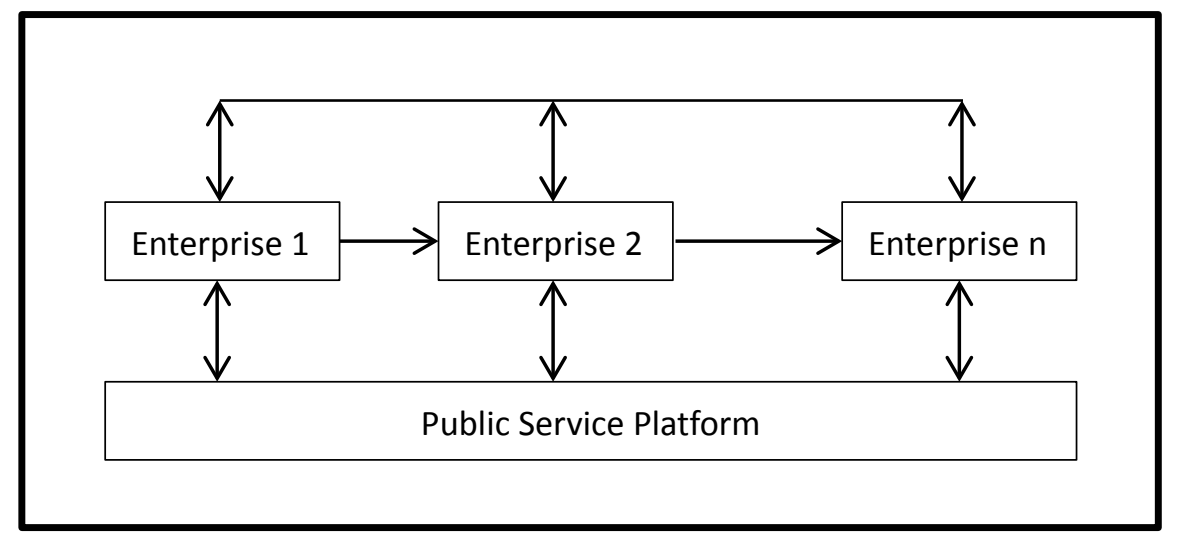

Figure 4-2 Middle Cycle 


\section{The large cycle of the society}

The large cycle is usually operated by the government and public people behave canonically. By recycling and reusing all kinds of different sources including emissions, the society like towns or cities will have a completely circular economy system.

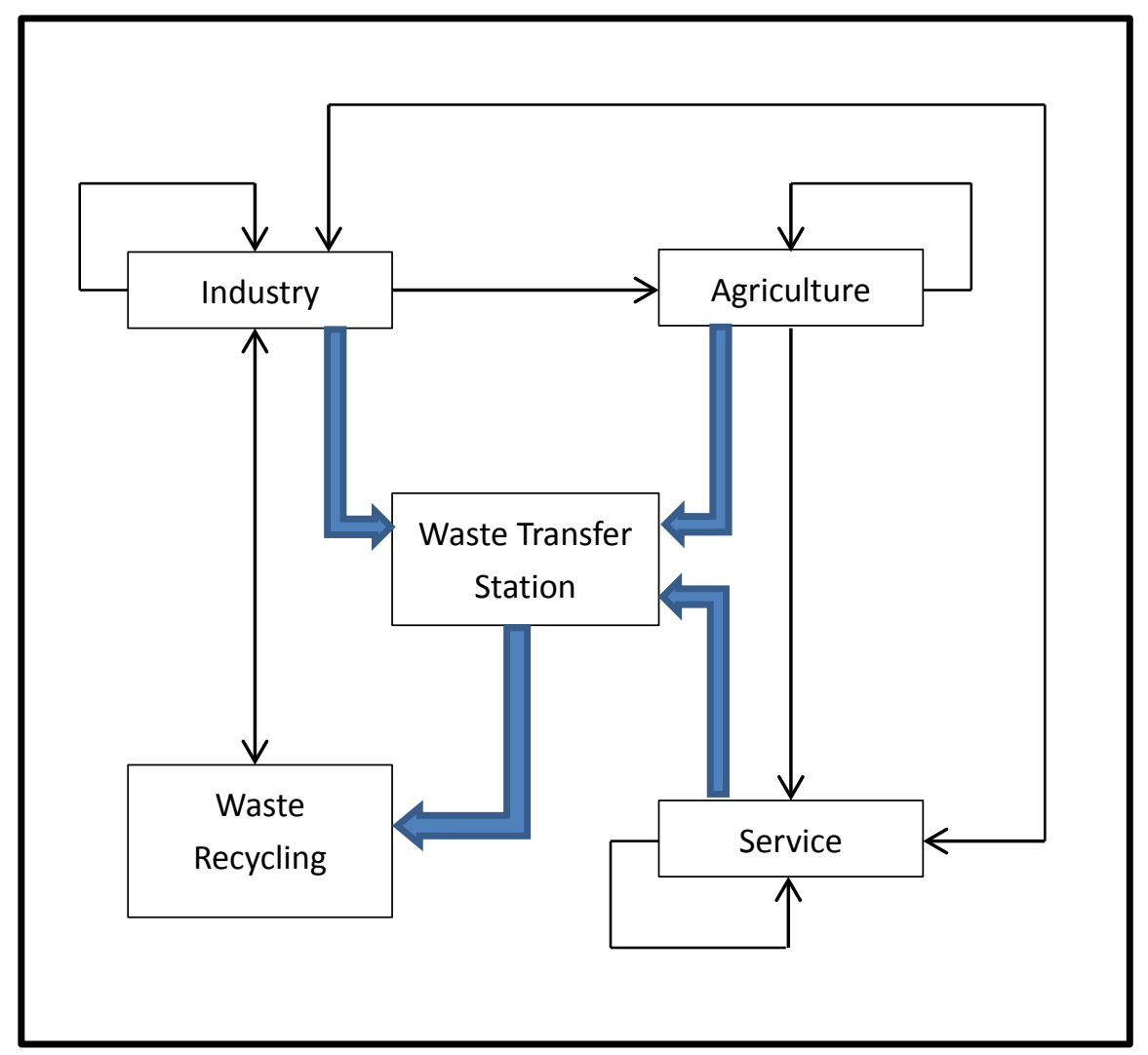

Figure 4-3 Large Cycle 


\subsection{Circular economic model}

Then, the following figures show the basic structure of the evaluation model of the regional circular economy. The superior part of this figure is the traditional economic structure.

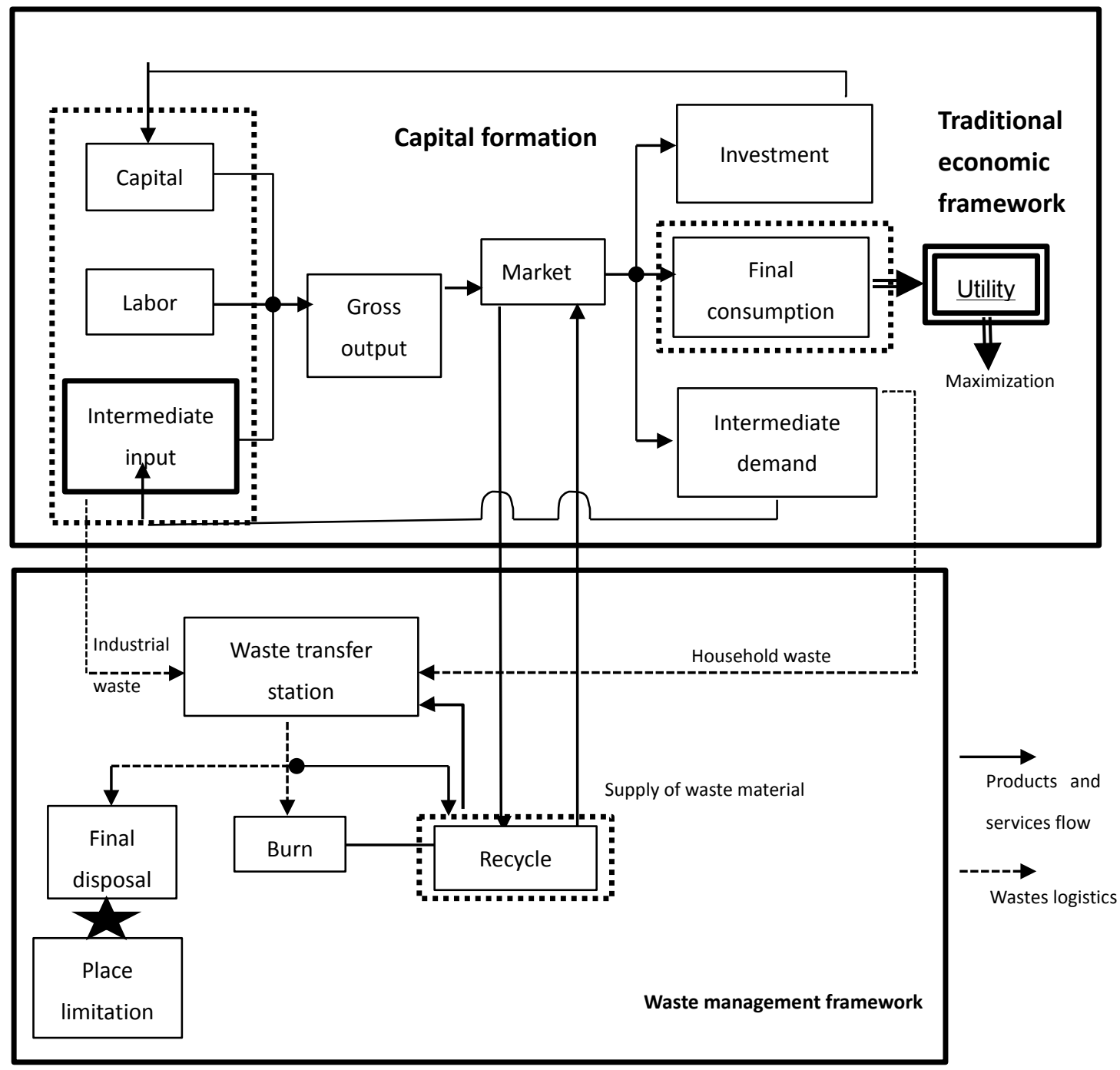

Figure 4-4 Circular economic model 
From the Figure 4-4, the production department invests capital, labor and intermediate input to produce. And the output will be distributed through the market and it will get into the consumption departments as final consumer goods, or get into the production department as investment, or get into the production department as the intermediate input. The bottom half of this figure is about the waste management system. It is the new part of the circular economic system. The waste of the production department and the consumption department will get into the recycle departments after the classification in the waste transit department. The recycling department will not only provide the recycling raw material for the market, but also produce waste, and the waste will flow back to the waste transit department.

Considering the framework model, these parameters may be used:

U: utility, Y: the economic output, C: the final consumption, X: the intermediate input of the economic sector, R: the economic output of circulation sector, XR: the intermediate input of the circular sector, I: the investment of the economic sector, IR: the investment of the circular sector, L: the labor of the economic sector, LR: the labor of the circular sector, Z: the input of the waste reduction, K: the capital stock of the economic sector, KR: the capital stock of the circular sector, $K Z$ : the capital stock of the waste reduction, W: the waste for reduction, $D$ : the waste for directly final disposing, Q: the waste for recycling.

Then the model equation may be written as:

$$
\mathrm{U}=\prod_{i} C_{i}^{\alpha_{i}}
$$

s.t.

$$
\begin{aligned}
Y_{i}+R_{i}=\sum_{j} X_{i j}+\sum_{j} X R_{i j}+C_{i}+\sum_{j} I_{i j}+\sum_{j} I R_{i j}+Z_{j} \\
\quad \mathrm{i} \text { and } \mathrm{j} \text { indicate the economic sectors }
\end{aligned}
$$

The limited availability of the data in China is an important factor to describe the model. As an economics model, more work should be done in the future. 


\section{Chapter 5 The construction and operation}

\subsection{The current situation of Shanghai}

Shanghai is the largest city by population in China and the largest city proper by population in the world. It is one of the four direct-controlled municipalities of China, with a total population of over 23 million as of 2010. It is a global financial center, and a transport hub with the world's busiest container port. High density of population, lack of natural resources and limited environmental land make it extremely important to develop circular economy system.

1. The industrial department developing status

Since 1995, Shanghai has carried out to establish Sino-British joint venture to develop cleaner production projects. In 1999, Shanghai has identified the metallurgical, chemical, pharmaceutical, textile, shipbuilding, electronics, building materials these seven major industries in Shanghai pilot sectors, strengthening development and utilization of clean production technology, to find out an effective way about the implementation of the product life cycle with low consumption and less polluting. In 2003 , the Shanghai municipal government set up a joint system to promote cleaner production. In 2005, Shanghai completed 50 enterprises pilot process.

In addition, Shanghai has also been striving for the construction of industrial eco-parks, and at present, Shanghai Caohejing New Technology Zone and Shanghai Chemical Industry Zone have begun their pilot work, and the latter one, as a pilot project of the cyclic economy, has enabled those enterprises in it to cut down $30 \%$ of the entire investment due to the maximum of the raw material resource utilization, thus, basically forming an integrated industrial chain of the cyclic economy, and achieving the mutual supply and sharing of chemical raw materials, intermediates, products, by-products as well as wastes among enterprises. According to the entire planning, Shanghai Chemical Industry Zone will also be constructed to be a world-class "Green Chemical Industrial Zone" by mutually supplying and sharing the raw materials and resources after linking with Jinshan Petrochemical. Shanghai has ranked forefront of the whole country in the 
comprehensive utilization of the industrial solid wastes, the rate of which reached $97 \%$ in 2003 . With 1.822 billion tons of the city's wastewater discharge, the total attainment rate of the industrial waste water was as much as $94.94 \%$ in that year. Also, with $100 \%$ comprehensive utilization rate, a total of 4.64 million tons of the fly ashes produced were reused mainly for the construction of walls, concrete, road construction, backfilling and cement production. In the eyes of those smart entrepreneurs, rubbishes are misplaced resources, which could also be regarded as the "gold mine" that has attracted an increasing number of entrepreneurs in Shanghai. According to the operator of a restaurant kitchen garbage disposal plant in Xuhui District, every 10 tons of hogwash can be processed into 2 tons of high-quality organic fertilizer, with a daily profit of nearly 2000 Yuan made by one disposal equipment. Shanghai Green Technology Knitting Co. Ltd. exported zizania leaves weaved and knitted products to Japan and achieved the output value of 38.65 million Yuan last year. After 10 years of exploration in the comprehensive utilization of resources and the cyclic economy, the cement company of Shanghai Building Materials Group has also generated a pretty decent result of the annual comprehensive utilization of over 60 tons of industrial wastes, accounting for $1 / 3$ of the cement output, eventually becoming the most influential enterprise of industrial wastes disposal in that field in Shanghai. In accordance with the principle of "Striving for the economic development with the conservation in the first place by improving the resource utilization efficiency", Shanghai has actively carried out lots of effective energy-saving and cost-reducing activities, making it in the leading position of energy conservation in the entire country. In 2003, Shanghai's energy conservation per unit of GDP was equivalent to 1.4 million tons of standard coal, and the energy consumption per ten thousand Yuan of GNP dropped to 1.07 tons of standard coal, far lower than the national average level (2.6 tons of standard coal). The comprehensive energy consumption saw a fall of nearly $75 \%$ compared with that of 1990, achieving the goal of the gross energy consumption growth rate lower than the speed of national economic development. In addition, as one of the primary "water-saving cities", Shanghai's water consumption was only 184 cubic meters for per ten thousand GDP in 2002, and other city water-saving indexes were all in the lead in china. In terms of the industrial water-saving, 
Shanghai also did a great job through the transformation of water-saving technology, the promotion of clean production, the wastewater treatment and the reduction of pollution discharge, with an industrial water recycling rate of $79 \%$, which was the top level in China. Shanghai Municipal Economic Commission has organized and compiled The Cyclic Economy Construction Guidelines of Shanghai Industrial Zone, establishing an evaluation system of the cyclic economy mainly made up of 6 indicators of the economic benefit, the development potential, the resource consumption, the eco-environment protection, the cyclic utilization as well as the infrastructure construction. For example, in terms of the eco-environment protection, the data is like 150 tons of net water consumption per ten thousand Yuan of GDP, the comprehensive energy consumption (equivalent to 1.35 tons of standard coal) per ten thousand Yuan of GDP, not less than $30 \%$ of greenery coverage rate in the park, not less than $90 \%$ of industrial solid waste utilization rate, etc. Each indicator has also been set up with several subsidiary indexes with the corresponding reference values, and in comparison with which, the scientific evaluation can be made for the effectiveness of the cyclic economy construction of the industrial zone.

\section{The agricultural department developing status}

In order to realize the sustainable development of agriculture, to secure an adequate supply of the city agricultural and sideline products and to maintain ecological balance, Shanghai needs to stick to the cyclic agricultural development due to its shortage of agricultural resources. Shanghai Municipal Party Committee and the City Hall have always attached great importance to the coordinated development of economy and environment, so Shanghai's taken the lead in the transformation of the agricultural production mode, the cyclic agricultural development, so as to realize the sustainable development of agriculture, and to ensure the safety in agricultural production. In recent years, Shanghai has increased farmers' income and the agricultural efficiency and has realized the sustainable development by land saving, water conservation and resource recycling.

(1) To keep the dynamic balance of cultivated land resources in the suburbs in the combination of 
protection and intensive utilization.

As the most valuable agricultural resource in Shanghai, the cultivated land has suffered from the severe imbalance between supply and demand due to the city construction, which has attracted great attention by the City Hall, and the three major measures below have been taken to cope with this problem.

The first one is to reclaim the tidal flats resources in a planned way. From 1949 to 2000, the total reclamation area of the tidal flats is 80,000 hectares, of which about 47,000 hectares have been used for agricultural production, effectively reducing the shortage of farmland. It's planned to reclaim 40,000 hectares more from 2001 to 2010.

The second measure is to vigorously promote land development and consolidation as well as the reclamation. In 2003 , the city accomplished the land consolidation and reclamation area of 9,333 hectares, with 3,000 hectares of arable land, at the same time, completing 3 reclamation projects with 5400 hectares of arable land.

The third one is to save and utilize the land intensively. According to the data collected from the first batch of 15 pilot families participating in the current replacement of the homestead, the homestead area has reduced to 398 hectares from the original area of 873 hectares after replacement, saving a total of 475 hectares which accounts for $54.4 \%$ of the entire homestead area. Also, after the recent industrial park carding, the number of the city's industrial park has declined to 79 from over 170 previously, increasing the industrial land utilization rate dramatically.

(2) To accomplish the scientific and rational utilization of water resources through both the protection and conservation

As a coastal city, Shanghai possesses abundant upstream water, but due to the surface water pollution, it has become a water quality-induced water shortage city. Therefore, the following 
measures need to be taken to protect the water resources.

The first one is to implement the comprehensive improvement of water environment particularly in river dredging. Since 1998, according to the requirements of "clean water surface, undefiled river bank, large depth of water and green shore", Shanghai has invested 100 million Yuan annually, cumulatively dredging 19,191 waterways of 16,384 kilometers and 228 million cubic meters of earth, and significantly improving the rural water environmental quality after rectification.

The second measure is to reduce water pollution emissions through the livestock and poultry farms management. Since 1999, the city has completed the fecal sewage treatment in a total of 153 large-scale livestock and poultry farms, and has closed, stopped, merged and transformed 733 ones with heavy pollution and unreasonable layout. The number of suburban large-scale livestock and poultry farms has declined from 1600 to 867.

The third one is to develop water-saving agriculture, and to improve the utilization of water resources. After vigorously strengthening the construction of water-saving irrigation facilities, the area of row irrigation, drip irrigation and hidden irrigation of vegetables has reached 6,667 hectares. By the promotion of land-based aquaculture method, per cubic meter of water can produce 50 - 60 kilograms of aquatic products, and the water resources can also be recycled. In addition, the aerobic rice researched currently has gained $50 \%$ of water consumption savings.

(3) To make wastes profitable by increasing the cyclic utilization of agricultural wastes.

The agricultural wastes in Shanghai mainly consist of the livestock and poultry manure, crop straws and old leaves of vegetables. How to make scientific use of them and how to make the waste to treasure is becoming an important issue of the agricultural development of cyclic economy.

The first measure is to be committed to the development of commercial organic fertilizer processing. Supposed that until 2007, the whole city's got a total of 3.41 million standard pigs, they 
will produce 1.65 million tons of fresh manure, which will be really huge resources available. The target is to apply the commercial organic fertilizer once three years for the basic farmland, which will enhance the pollution control of livestock and poultry manure, reduce the amount of chemical fertilizer, improve the quality of cultivated land, restore the ecological chain, promote the production of high quality agricultural products, and also maintain the sustainable development of agriculture significantly.

The second measure is to reinforce the comprehensive utilization of corp straws. In a certain proportion, straws and excrements can be processed into high-quality organic fertilizer. Also, the relevant departments have developed a sort of straw baler, and the technology of producing building board in the use of straws, which have improved the straw utilization rate and have greatly decreased the rural straw burning.

The third measure is to promote the clean vegetables into the city, which has been basically implemented in the suburbs at present. And the old vegetable leaves and rhizomes, accounting for about $25 \%$ ( 1 million tons) of the entire vegetable output, could be used as fertilizer after processing and fermentation, which has not only increased the soil organic matter, but also reduced the city wastes.

In terms of the cyclic economy in rural areas, Qianwei Village of Chongming County has made great achievements. A complete plan has been formed to establish the village into a "demonstration park of modern urban ecological cyclic agriculture", and the special supply base of the green organic agricultural products for the 2010 Shanghai World Expo. According to the overall planning, Qianwei Village will also strive for the development of ecological agriculture, ecological tourism and ecological environment education, mainly based on which, forming an special "three-eco" economic recycle chain. Also, in consideration of the sewage water quality and the eco-agricultural park construction features in the village, a combination mode of treatment and reutilization will be adopted for the life wastewater treatment. As for the treatment, the village will 
use the wastewater treatment technology of constructed wetlands, basically made up of the anaerobic pretreatment, wetland treatment and farmland irrigation or excretion. The utilization treatment namely means to return the sewage back to the farmland by making full use of artificial wetland disposal system and farmland fertilization pipe networks, of which the former one is used to preprocess the sewage through the anaerobic hydrolysis tank, and the latter one is used to discharge the sewage directly into farmland by linking with the pipes. According to the plan, Qianwei Village will also select "four in one" energy ecological model, namely a new production mode in combination of the courtyard economy and ecological agriculture. On the basis of the land resources, It will adopt the energy conversion technology to link the methane tank, the pig house, the toilet and the solar greenhouse in the fully closed state on the farmland powered by solar energy, linked with the methane, combined planting with breeding combination, so as to constitute a comprehensive energy utilization system in the entire village.

\section{The consumption's situation}

By selling the old newspapers, waste glass bottles, empty cans to the recycling station -- Shanghai citizens have already done a lot in recycling their household garbage, and there have been far more wastes reused than these things. For example, in Qingpu District, the abandoned water bamboo leaves have been redesigned and processed into much more expensive crafts by many farmers, and have also been exported to Japan; the discarded Tetra Paks have been recycled by Shanghai Choi Lok environmental product company, and have "changed" into pieces of material plates after being washed, crushed, heated, and pressed,; a larger number of branches left after trimming the street trees in Spring have now become the indispensable raw materials of Shanghai Galaxy Artificial Board Factory; even the kitchen garbage, the livestock and poultry manure can also be processed into organic fertilizer; those wastes in the garbage treatment plants can be combusted to generate heat energy for power generation. According to the city waste management office, around 500-600 thousand tons of household garbage has been recycled every year in Shanghai at present, which has been geared to international standards. 
Since June of 2000 , Shanghai has begun the implementation of garbage collection, and a variety of methods have been adopted to dispose the household garbage. In order to establish a circulation system of kitchen garbage disposal, and to make effective and scientific use of those kitchen waste resources, the Shanghai Municipal Science and Technology Commission has developed a scientific research project on "the Research and Development of Technique and Equipment of Fodder Regeneration from Kitchen Leftover". This nearly two years of project has significantly reflected all the features of the cyclic economy as follows.

(1) Greatly increasing the utilization rate of kitchen garbage by transforming the numerous discarded wastes into the raw materials;

(2) Reduce environmental pollution. As a sort of resource in the special collection, transport and disposal system, the kitchen garbage has not only cut over pollution of land and water environment, but also cut off the spread of pathogenic bacteria through food chain caused by direct animal feeding;

(3) Bringing about favorable economic benefits, like the renewable $60-70 \mathrm{~kg}$ of animal feed (1200 Yuan) from per ton of kitchen wastes. Also, every day in Shanghai city, 1000t kitchen garbage produced has been recycled to regenerate 70t animal feed with 84 thousand Yuan of the output value, and around 30.66 million Yuan of annual production value; in addition, in terms of the harmony between human and nature, if planting feed grain, per mu of land will gain $500 \mathrm{~kg}$ of annual production, but the total 360 thousand tons of kitchen wastes produced in Shanghai every year can be processed into 25.55 thousand tons of high protein feed, and if which is used to replace the traditional feed grain, like corns, wheat and soybeans, 51.1 thousand mu of land resources will be saved. Putuo District City Management Bureau has set up a waste disposal center to make a series of researches on the recycling and utilization of kitchen wastes and the 
development of animal feed. It has also built up a mechanized production line with a daily processing capacity of 40 tons of food wastes.

Since 2000, Shanghai has promulgated and implemented The Interim Measures of the Management of Disposable Plastic Boxes", stipulating that the relevant administrative department shall charge the pollution treatment fees of 3 cents per box from the disposable plastic box factories as the recycling funds, among which, 1 cent is the labor fee for the junk recycler, and the others are used as the transport, management and disposal subsidies. Economic benefits are an effective incentive to the enthusiasm for recycling, but a reasonable disposition is the fundamental preventing solution to the secondary pollution. A basic industrial chain has already been so greatly formed from the production to recycling and reutilization of the disposable plastic boxes that the recycled boxes have all been sent to two recycling factories in Kunshan and Putuo District of Shanghai. And the plastic particles made from discarded plastic boxes can be made into building materials, plastic shells, shoe heels and stationeries which are always in short supply. A total of 3687 tons of reprocessed plastic particles have been manufactured in the past 5 years, and the price has also soared from 800 yuan per ton to several thousand Yuan per ton. The kitchen garbage, namely the leftovers, as a sort of extensive resource, can be produced from wastes of families, restaurants, canteens, food processing factories, and the expired goods of the non-staple food markets and supermarkets, etc.

\section{The recycling and regeneration department situation}

As shown in the following table 5-1, the total amount of industrial, agricultural, city constructional and residential emissions in Shanghai was around 50 million tons in 2003. Shanghai has reached the national advanced level in renewable resource recycling. At present, it has been striving to strengthen the recycling network construction, so as to improve the comprehensive management system, and to make some progress in this field.

In September of 2001, a clear preliminary idea of construction of the renewable resource recycling 
network was put forward in Shanghai and was put into practice as a practical project of the City Hall in 2002 and 2003, during which, 176 "trading stations" have be established, a number of mobile "collection points" have been set up in each residential area, and 2 "sorting fields" have also been built through bidding; In 2004, 96 new "trading stations" were also established. But those "fields", "stations" and "points" have only emphasized on the collection, transport, sorting and distribution of renewable resources, but not on the construction of renewable resources processing methods and terminal network system. Therefore, there are still a series of problems to be resolve, such as the further improvement of the comprehensive coordination mechanism among administrative departments, the formation of the industrial chain, and the construction of the trading market.

Table 5-1 The Waste Production of Shanghai in $2003^{1}$

\begin{tabular}{|l|l|l|l|}
\hline & \multicolumn{1}{|c|}{ Details } & \multicolumn{1}{|c|}{ Amount (ton) } & \multicolumn{1}{c|}{ Using } \\
\hline Industry & Coal ash, slag & $16,590,000$ & Road, construction \\
\hline Agriculture & Straw, excrement & $9,000,000$ & Farmland, organic fertilizer \\
\hline Building & $\begin{array}{l}\text { Mud, muck, building } \\
\text { waste }\end{array}$ & $20,000,000$ & Bricks, farmland, land reclamation \\
\hline Residence & Household trash & $5,850,000$ & Burning, landfill, compost \\
\hline
\end{tabular}

\subsection{The construction of the circular economy system}

The salient features of Shanghai, an oversized international metropolis, are a huge population, poor natural resources and a limited environmental carrying capacity. It is therefore quite important to construct a relatively complete and comprehensive circular economic system for this city. Shanghai is also trying to establish itself as international economic, financial, trade and maritime center, and tackling pollution and other environmental issues is an important step in this process. Based upon the development process described previously, in this section the author will seek not

${ }^{1}$ Development Report of Shanghai Circular Economy (2005) 
only to describe a more comprehensive industrial system that promotes the circular economy at the enterprise level, the industrial level and the social level, but also to elucidate the changes necessary at the overall societal level, in order to address the environmental problems caused by production and consumption within the city.

1. The cycle at the enterprise level

The construction of the circular economy at the enterprise level in Shanghai should be based upon the following three aspects.

Firstly, the enterprises in Shanghai should be transformed from traditional enterprises into recycling enterprise. In order to improve ecological efficiency, the enterprises should work to achieve cleaner production processes and transform their traditional production technology into cleaner production technology. This can reduce resource consumption, energy consumption, water consumption and the waste emissions per unit produced.

Secondly, new enterprises should be assessed for whether their production technologies and processes can meet the goals of circular economic development. Enterprises that cannot meet these requirements would have to alter their production technologies and processes in order to meet the standards of the circular economy.

Thirdly, mandating the use of cleaner, recycling-based production technology by enterprises is essentially changing some of the social cost of pollution into private cost, potentially placing significant economic pressure on these companies. As recycling technology is not yet fully mature, requiring companies to study and apply this technology requires a large amount of capital investment and risk on their part, potentially reducing the enthusiasm of these companies to implement ecologically friendly production processes. The government of Shanghai should hence take some measures to assist these companies in the transition process. 
The government should study the economic behaviors of these enterprises and take some actions to encourage their adoption of circular economic practices, such as offering them financial preference and economic subsidies. This would make realizing the circular economy in the enterprises' own economic interests. The government should also support research on technology beneficial to the circular economy in order to promote its further development. In addition, the government should enact harsh punishments on those enterprises that waste large amounts of resources without reusing and recycling.

An example of such measures in action is when the chemical factory Jinwei Corporation was fined by the Court of Jinshan District in Shanghai due to its uncontrolled emissions, which had polluted the Yangtze River and caused a water crisis at the beginning of $2013^{2}$.

2. The cycle at the industrial level

The most typical representative of the circular economic system is the ecological industrial park. There have been some such demonstration projects constructed as part of the development of the circular economy in Shanghai.

The Shanghai Chemical Industrial Park, for example, is a pilot of the circular economic mode of production. It utilizes insights gained from the study of advanced industrial parks across the world, and links up the different companies involved in the production process according to the particular characteristics of various stages in the chemical industry supply chain. The waste of one company can become the raw material for other companies; the heat produced by one company can become the energy fueling others. The efficiency of resource utilization can hence be greatly improved, with the input requirements of enterprises also being reduced in this process.

${ }^{2}$ Eastday Shanghai Website: http://sh.eastday.com/m/20131010/u1a7704702.html 
Ecological enterprise arrangements can not only reduce the economic cost of dealing with waste, but also allow the recycling of waste into new value sources. Transaction costs between enterprises will however increase as the trading volume of such recycled waste increases, and thus the establishment of the circular economy at the industrial level can benefit from government action to address these costs.

Firstly, following the theory of the circular economy, the government should make an overall plan for ecological industrial parks that involves grouping together enterprises and projects that have complementary functions. Whole high-tech zones should also be planned with the necessities of the ecological economy in mind, with the government encouraging the enterprises within such zones to take the life cycle perspective and ecological design methods into account in order to minimize resource consumption and waste production in the production cycle and improve the efficiency of resource use. The development of new high-tech zones should involve choice of enterprises based upon their suitability for the application of circular economic concepts, and a sophisticated industrial network should be constructed in order to achieve an arrangement of enterprises in the park optimized to minimize resource use. Old industrial areas should be encouraged to alter their production processes based upon the principles of the circular economy.

Secondly, the government should also develop infrastructure and improve policies regarding the city's water, electricity, gas and road infrastructure systems based upon advanced environmentally-friendly technology, and design them in such a way as to benefit enterprises' efforts to engage in the development of the circular economy. Preferential policies in terms of taxation, credit, import and export should be implemented for enterprises participating in the transition to a recycling-based economy.

Lastly, the government should develop intermediary service organizations to coordinate and guide the transfer of information, technology and materials between industrial parks and the enterprises 
occupying them. This can improve the ability of such parks to minimize resource waste. Along with the Shanghai Chemical Industrial Park mentioned above, the Shanghai government has also established a region called the Shanghai International Chemical Manufacturing Industrial Service Zone, which has been designed to interoperate with the Shanghai Chemical Industrial Park in such a way as to smooth and quicken the development process of the circular economic system.

\section{The cycle at the social level}

In order to establish resource circulation at the social level, the key is to establish links between the different levels in the circular economic system. In the production process, the waste of enterprises upstream will become the raw materials of enterprises downstream. Municipal solid waste should similarly be recycled; the whole city and even the whole society should be included into the circular economic system. Creating connections between sustainable production and sustainable practices in citizens' daily lives works towards forming a sustainable development cycle at the overall societal level.

An example of this is how Shanghai recently constructed a new model for online waste recycling. Waste trading network centers have been established to allow citizens to sell the waste and unwanted materials generated during their daily lives, with these waste products then being transformed into a useful source for production and consumption via the secondary trading market. Some of them will also be sent directly to enterprises as the raw materials for new production. To further develop upon this innovation, the government of Shanghai should also take the following steps.

Firstly, the government should make a plan for building an ecological city, and make use of market mechanisms to promote the development of ecologically sound economic practices among industries. This plan should include such actions as building a circular system for the classification and recycling of municipal wastes, and constructing a circular economic industrial system by considering the four categories of industry as a whole and unifying the flows and circulation of 
materials and energy between them.

Secondly, the government should establish an information exchange platform. The traditional method of information exchange between organizations is asymmetric, and this must be changed in order for proper coordination of the circular economy to be realized. Entities producing waste should have to provide detailed information on waste materials, including their design and composition, to the entities responsible for material circulation and recycling, and these material circulation entities should in turn provide the waste producing entities with the best possible technology and methodology for ecologically sound waste disposal and transfer.

\subsection{The structure of the supporting environment}

This section will analyze the supporting environment within the circular economy. Firstly, the integrity of the system will be considered. The author will propose the considerations necessary for constructing a supportive environment for the Shanghai circular economy, from the perspective of four aspects including technology, economy, policy and socio-cultural issues. Second, the particular characteristics of Shanghai and their relation to the development of the circular economy within the city will be addressed.

An example of these particular characteristics is Shanghai's status as an International Economic, Financial, Trade and Shipping Center, which makes any environmental problems resulting from consumption in the city of particular concern due to their potential effect on the city's image. As Shanghai is an oversized international metropolis, it is characterized by high population density, poor natural resources and a limited environmental carrying capacity, which are also factors that make the development of a circular economy of particular importance to the city.

1. Technical supporting system

(1) Promoting the development of the related theory and technology 
The individual stages in the circular economy such as minimization, reuse and recycling cannot be separated from the need for advanced waste processing and conversion technologies, facilities and equipment. Scientific and technological development is therefore an important factor in the development of the circular economy, and the government should promote the development of and invest in research on the following areas: reducing the energy and material consumption of production processes, developing cleaner production technologies that produces less pollution, improving the lifetime of materials, researching and developing new materials to replace toxic and contaminated materials, developing renewable resource technologies and waste recycling techniques (such as constructing functional electrical appliances, batteries, and computers from waste products), improving the efficiency of resource use, developing better predictive models, and studying the stability of the ecological practices of different industries and enterprises.

(2) Promoting the technological transformation towards the circular economy The government should encourage the development of the tertiary industry and of high-tech industries with low resources consumption and high added value. Traditional industries should be transformed by the application of clean, advanced technologies, which would improve their ability to make efficient use of natural resources and hence help protect the environment.

(3) Develop the technological system of the circular economy

The circular economy should be supported by the technology of minimization. Innovation should be pursued towards meeting two objectives. The first objective is the development of the general technology of the circular economy, including methods for such things as logistics analysis, life cycle assessment, environmental design and the construction of ecological industrial parks. The assessment of the input, output and impact on the environment of a particular element within the circular economy should be based upon an analysis taking into account the comprehensive effects of this element on the whole economic and ecological process, rather than an analysis limited only to simple localized effects. The second objective is the development of specific technology 
relevant to particular industry sectors within the circular economy, such as the chemical industry, metallurgy, construction, services and textiles, as well as technology relevant to making the daily actions of citizens such as traveling, eating and dressing as environmentally friendly as possible.

\section{(4) Technology exchange}

The Baosteel company represents an example of ecologically friendly development. Academic and technological exchanges are an integral part of green development, and Baosteel has continuously emphasized and actively participated in such exchanges. On March 15th to 16th, 2014, the "China Iron \& Steel Enterprise Energy-Conserving Technology Seminar" was held by Baosteel, with experts and scholars in the field of iron and steel manufacturing, including Anshan Iron \& Steel, Wuhan Iron \& Steel, Shougang Jintang Steelwork, Taiyuan Iron \& Steel, Jinan Iron \& Steel, Magang (Group), Tangshan Iron \& Steel and Anyang Iron \& Steel, as well as industry associations and institutions of higher education including the China Iron and Steel Association, the University of Science and Technology Beijing and Northeastern University, being invited to gather at Baosteel to exchange views on and explore the application of energy-conserving technologies in iron and steel enterprises. They discussed their relevant practical experiences and considered various energy conservation and emission reduction solutions to meet their environmental obligations under China's "Twelfth Five Year Plan", working to determine how best to effectively facilitate the success of the energy conservation and emission reduction efforts of China's iron and steel industry.

\section{Policy supporting system}

The local government plays an important role in the development of the circular economy. It is not only the designer and promoter of ecologically sound systems and rules, but also the supervisor of laws and regulations. It can hence guide and promote the development of the circular economy by means of developing appropriate regulations and implementing preferential policies for firms that engage in recycling and clean production. 
(1) Proposing policy mechanisms for promoting the circular economy

Achievement of the environmentally efficient allocation of resources requires the government to establish a series of systems, which can be divided into three categories. The first category is that of environmental systems, including the resource system, the property rights system, the market system, the industrial system and the technological system. The second is that of normative systems including the production system, the consumption system, the trade system, the packaging system and the recycling system. The third category is that of incentive systems, including the financial system, the tax system, and the investment system.

\section{(2) The exemplary role of the government}

The government should carry out consumption education and guide the public to participate in the recycling economy. The government should play an exemplary role in consumption in terms of supporting the circular economy, giving priority to the purchase and use of goods produced via recycling. It should also pay attention to the conservation of the resources it uses, take the initiative to recycle its waste wherever possible.

(3) Mobilizing the functions of local government

The government bears the main responsibility for the development of the recycling economy. The market system in China is not perfect, and the market cannot effectively play the role of allocating resources in an environmentally efficient manner. The government should therefore make full use of the administrative means available to promote and regulate the circular economy and ensure sustainable development.

(4) Make full use of the market mechanism

The government should make use of the market to promote the enthusiasm of enterprises for environmentally friendly development. The development of the circular economy essentially 
follows ecological and economic laws in its activities; the cycle of the natural elements requires some external input, and similarly the circular flow of materials in an economic system also requires some investment. For enterprises, this investment is an opportunity cost, and if there is no benefit to them then the enterprises will not eagerly engage in the development of the circular economy. The government should therefore institute policies that are preferential to the development of recycling-based enterprises, such as tax relief and infrastructure investment, to make ecological development profitable for them. The government must continue working to convert the societal externalities produced by polluting enterprises into internal costs to those enterprises, which will incentivize them to reduce their emissions. Increased effort must be made towards enforcing environmental laws and regulations, as these policies are vital for the development of the circular economy within the market environment.

\section{Economic support systems}

The development of economic support systems for the Shanghai circular economy can be divided into two aspects: further developing the existing national economic accounting system, and improve existing circular economic systems.

Firstly, the government and enterprises should study and construct green fiscal accounting systems. Traditional methods of national economic accounting such as Gross Domestic Product does not take into account the economic damage caused by resource consumption and environmental pollution. Green Gross Domestic Product, on the other hand, is equal to the GDP minus capital depreciation, depletion of natural resources and the loss of the ecological resources, and so presents a clearer picture of the costs of unsustainable development practices. Establishing a circular economy therefore requires reform of the current fiscal accounting system. A set of green fiscal accounting systems should be established at all levels, including the enterprise level, the regional government level, and the national level. These systems will exist in parallel with the traditional accounting system in order to allow a comprehensive and objective 
evaluation of the state of the economy. Comprehensive evaluation index systems relating to the circular economy should also be established, measuring such things as resource productivity, rate of decrease of resource consumption, material recovery rate, and the proportion of materials recycled, and these indexes should be gradually incorporated into the national economic and social development plans.

Secondly, the government should establish effective policies for encouraging the development of the circular economy. Industrial policies should encourage the growth of low resource-consumption and high value-added industries and promote the development of sectors that contribute positively to the development of the circular economy. Financial and taxation departments should provide financial support and tax relief to enterprises that make significant use of recycling and utilize renewable resources, in order to improve the competitiveness of renewable resource products on the wider market. The price formation mechanism of natural resources should also be improved and refined so as to adjust the price relationship between raw resources and the final product produced from them, in order to promote the development of the circular economy.

\subsection{The external environment of Shanghai circular economy}

1. The creation of a clean natural environment

The creation of a safe and pollution-free natural environment will protect the environment and make the living conditions of citizens healthier and more attractive, and the development of a circular economy is quite conducive to this goal. As Shanghai faces a severe shortage of natural resources and its ecological capacity is quite limited, protecting the natural environment is of particular importance, and hence Shanghai is particularly well placed to benefit from the circular economy. To further address environmental issues, Shanghai should take the following measures.

Firstly, the Shanghai government should deal with atmospheric pollution problems. Mitigating such 
problems requires treatment of the sources of pollution within the city. The main objective of atmospheric environment management is not only to maintain suitable air quality, but also to ensure that there is adequate supply of clean atmosphere. It is therefore important not only to reduce the quantity of pollution sources and pollutant emissions, but also to promote clean air circulation, regeneration and filtering.

Secondly, the problems of water resources pollution must be solved. Water is a natural resource required for the survival of all living systems. In a city, its primary uses are drinking, washing, and various industrial processes. Water resources can be better managed by such things as collecting storm water and preventing the entry of pollutants into the water supply. It is also necessary to promote the quality of the water that is returned into the river system to ensure that the ecological quality of the city's rivers is not further degraded.

Thirdly, the land, plant and animal resources in Shanghai are quite limited. The government should therefore guarantee a certain amount of land for the construction of green belts to support the renewal of plant and animal life throughout the city. This would then serve as a catalyst for the protection and development of the urban ecosystem's biodiversity. Urban green structures can include such things as cultivated land, parks, afforestation structures and natural forests.

\section{The creation of a supportive social and economic environment}

The external environment to Shanghai includes not only the surrounding regions such as Jiangsu, Zhejiang and other cities, but the whole country and even the whole world. Shanghai can more easily develop a circular economy when its external environment is moving in the same direction. Environmentally sound legislation at the national level is particularly important, and one of the most effective ways for the government to protect and promote the development of the circular economy. China has already developed a relatively complete system of environmental laws and regulations, but there is no specific legislation pertaining to the circular economy. China should 
therefore learn from the experiences of other countries and develop applicable environmental laws and regulations suitable to the particular conditions of the Chinese environment. Shanghai, as the first large Chinese city to develop its circular economy, should lead the nation's scientific efforts towards this goal and hence contribute towards promoting the development of the circular economy across the whole country. The development of Shanghai's circular economy will also have an indirect positive effect on surrounding areas via positive externalities; environmental progress in Shanghai will benefit the environmental condition of the surrounding areas. Pollution and destruction of the environment in the surrounding areas will however produce negative externalities that are not conducive to the development of the circular economy in Shanghai, so Shanghai is not able to push the country forward alone, and hence should receive assistance from the central government towards developing the nation's circular economy.

In addition, areas that have significant trade relationship with Shanghai can also affect the development of the Shanghai circular economy. If Shanghai imports a product that has a serious negative environmental impact, then this product will have a negative impact on the circular economy of Shanghai. Shanghai should therefore work to strengthen cooperation with neighboring regions in order to work together with them towards improving the overall circular economy and environment.

\subsection{Performance of Baosteel}

The Baosteel Group is a typical enterprise arising from China's reform and opening-up. The construction of Baosteel commenced on the bank of Yangtze River in north Shanghai on December 23rd, 1978, only one day after the closing of the Third Plenary Session of the Eleventh CPC Central Committee. After over 30 years of development, Baosteel has grown into China's most competitive iron and steel group with the highest level of modernization. At the end of 2012, Baosteel had a total of 130,401 employees located all across the world. 
Here is the Green Manufacturing Performances of Baosteel during $2009-2012 .^{3}$

Note: All indicators in the table, except for "Comprehensive Utilization Rate of Solid Waste Resources", use 2009 as the benchmark year.

\begin{tabular}{lccccc}
\hline Name of Indicator & Unit & 2009 & 2010 & 2011 & 2012 \\
\hline $\begin{array}{l}\text { Comprehensive Energy } \\
\text { Consumption Per Ton of Steel }\end{array}$ & $\%$ & 100 & 96.64 & 98.55 & 102.62 \\
\hline $\begin{array}{l}\text { Total Amount of Waste } \\
\text { Energy Recovered }\end{array}$ & $\%$ & 100 & 99.93 & 113.81 & 93.92 \\
\hline $\begin{array}{l}\text { New Water Consumption } \\
\text { Per Ton of Steel }\end{array}$ & $\%$ & 100 & 97.46 & 98.38 & 101.62 \\
\hline $\begin{array}{l}\text { Sulfur Dioxide Emission } \\
\text { Per Ton of Steel }\end{array}$ & $\%$ & 100 & 61.71 & 50.86 & 45.95 \\
\hline $\begin{array}{l}\text { COD Emission Per Ton } \\
\text { of Steel }\end{array}$ & $\%$ & 100 & 88.84 & 83.74 & 90.32 \\
\hline $\begin{array}{l}\text { Fume Dust Emission Per } \\
\text { Ton of Steel }\end{array}$ & $\%$ & 100 & 91.65 & 88.75 & 92.31 \\
\hline $\begin{array}{l}\text { Comprehensive Utilization } \\
\text { Rate of Solid Waste Resources }\end{array}$ & $\%$ & 98.26 & 98.58 & 98.81 & 98.9 \\
\hline
\end{tabular}

Figure 5-1 Green Manufacturing Performances of Baosteel during 2009 - 2012

Here is the Green Manufacturing Performances of Bayi Iron \& Steel during $2009-2012 .^{4}$

Note: All indicators in the table, except for "Comprehensive Utilization Rate of Solid Waste

3 Baosteel Official Website: http://www.baosteel.com/group en/contents/2928/40179.html

${ }^{4}$ Baosteel Official Website: http://www.baosteel.com/group en/contents/2928/40179.html 
Resources", use 2010 as the benchmark year.

\begin{tabular}{lccccc}
\hline Name of Indicator & Unit & 2009 & 2010 & 2011 & 2012 \\
\hline $\begin{array}{l}\text { Comprehensive Energy } \\
\text { Consumption Per Ton of Steel }\end{array}$ & $\%$ & 100 & 89.85 & 88.42 & 86.87 \\
\hline $\begin{array}{l}\text { Total Amount of Waste } \\
\text { Energy Recovered }\end{array}$ & $\%$ & 100 & 146.21 & 159.75 & 190.91 \\
\hline $\begin{array}{l}\text { New Water Consumption } \\
\text { Per Ton of Steel }\end{array}$ & $\%$ & 100 & 81.28 & 68.95 & 65.30 \\
\hline $\begin{array}{l}\text { Sulfur Dioxide Emission } \\
\text { Per Ton of Steel }\end{array}$ & $\%$ & 100 & 73.50 & 69.17 & 54.69 \\
\hline $\begin{array}{l}\text { COD Emission Per Ton } \\
\text { of Steel }\end{array}$ & $\%$ & 100 & 53.41 & 47.60 & 24.53 \\
\hline $\begin{array}{l}\text { Fume Dust Emission Per } \\
\text { Ton of Steel }\end{array}$ & $\%$ & 100 & 109.49 & 89.79 & 56.35 \\
\hline $\begin{array}{l}\text { Comprehensive Utilization } \\
\text { Rate of Solid Waste Resources }\end{array}$ & $\%$ & 70.51 & 73.50 & 69.17 & 83.49 \\
\hline
\end{tabular}

Figure 5-2 Green Manufacturing Performances of Bayi Iron \& Steel during 2009 - 2012 Compared with Baosteel (Shanghai) and Bayi (Xinjiang), Baosteel has obvious advantages over Bayi Iron \& Steel.

Green manufacturing refers to the adoption of various management and technical measures in the iron and steel production process to maximize energy conservation and reduction of consumption and emission with the aim to realize clean production along with healthy economic returns and therefore harmonious co-existence with the environment of such production. In 2012, Baosteel invested RMB 1.522 billion in energy-conservation and emission-reduction projects and successfully completed a series of key energy-conservation and emission-reduction projects, including the energy-conservation reconstruction of No.1 steel-making converter furnace of Baosteel Co., Ltd., sintering and desulfuration reconstruction at Bayi Iron \& Steel headquarter, sintering and desulfuration reconstruction at Ningbo Iron \& Steel and construction of gas-fired boiler at Shaoguan Iron \& Steel Co., Ltd., despite the extensive losses suffered throughout China's iron and steel industry. 
As compared with 2011, the Group realized a year-on-year energy conservation of 483,000 tons of coal equivalent and reduced the emission of $\mathrm{SO}_{2}$ and $\mathrm{COD}$ by 16,585 tons (36\%) and 701 tons $(32 \%)$ respectively.

\section{Energy Management System}

Baosteel is the first to initiated certification for energy management system in China's iron and steel industry. In 2012, Baosteel Co., Ltd. (Headquarter) and Baosteel-NSC/Arcelor Automotive Steel Sheets Co., Ltd. passed the review for the three-year pilot of energy management system.

\section{Clean Production Review}

In 2012, Baosteel Stainless Steel passed the second acceptance inspection. Four entities, including Baotong Iron \& Steel and Jiangnan Rolls Company, passed the first acceptance inspection and three entities, including Changxin Slag Company, initiated clean production review. Yantai Bao-Mit Steel Distribution Co., Ltd. under Baosteel International passed the clean production review and was recognized as an outstanding "Clean Production Enterprise" of Shandong Province. This is a breakthrough in the implementation of environment management in Baosteel's processing and distribution services.

Management and Project Construction of Energy Conservation and Emission Reduction 2012 was a crucial year for the comprehensive implementation of the National "Twelfth Five-Year" Plan. Baosteel segmented the energy conservation and emission reduction performance targets, implement such targets at all levels and ensured full control over energy conservation and environmental protection indicators through dynamic monitoring, follow-up and strict accountability practices on a monthly basis.

Currently the country has launched the first group of carbon emission trading pilots in seven provinces and municipalities, including Shanghai, Hubei and Guangdong. In response to that, 
Baosteel has organized carbon emission trading right pilots at concerned entities and actively cooperated with Shanghai in the research on and establishment of the monitoring and statistical methods for carbon emission of Shanghai's iron \& steel industry.

In light of the requirement that all unit output energy consumption indicators should be appraised using comparable indicators during the National "Twelfth Five-Year" Plan and the difficulties in management of unit output energy consumption indicators by department, Baosteel has set up a comparable unit output indicator statistics and management system.

Active Exploration of the Application of New Energy Technologies

In order to accumulate experiences in on-grid photovoltaic power generation projects, Baosteel Co., Ltd. launched the "Energy Centre Building 130 KW Photovoltaic System Project" in March. The project commenced on-grid power generation in May and laid solid foundation for Baosteel's full involvement in solar photovoltaic power generation projects.

Baosteel Co., Ltd. has undertaken the implementation of the "Golden Sun Demonstration Project" in steelwork. The project, with an installed capacity of 50MW, is expected to generate 50 million $\mathrm{KWh}$ per year, making it the largest steelwork solar power generation demonstration project currently in China. The project generates power from solar energy absorbed directly by solar arrays installed on rooftops and occupies no land resources.

\section{Baosteel's Green Achievements}

In 2012, Baosteel's comprehensive energy consumption per ton of steel was $4 \%$ lower than the energy conservation and emission reduction target. $\mathrm{SO}_{2}$ emission was 16,600 tons less than the annual target. COD emission was 701 tons less than the annual target. Refer to the following table for details. Baosteel had no environmental-protection-related violations or any related penalties in 2012. 


\section{Chapter 6 Main findings and conclusions}

1. The circular economic theory is based on the reflection of the human's resources and environmental issues, and the simulation of the natural ecosystems.

2. The stages of development of the circular economy can be divided into four stages including waste recycling stage, the waste emissions reducing stage, zero discharge of waste stage and the whole social cycle stage.

3. Essentially circular economy is an economic and ecological development model. Its purpose is to conserve the natural resources, improve the efficiency of resource use, protect the environment and promote the sustained economic development and the overall social progress, and then from the whole, to achieve the human society in harmony with nature, fairness, virtuous cycle of interaction. Its principles are to reduce, reuse and recycle 3R principle.

4. The circular economy has some characteristics. First, it is the objective. Second, it is technological. Third, it is systemic and last it has different levels.

5. The theoretical basis of the circular economy includes economic foundation and natural science foundation. For the economic theories, the author mainly analyzed the economic theory of externalities theory and the theory of market competition. And for the natural science foundation, the author mainly analyzed the ecology principle and the first law of thermodynamics and so on.

6. This thesis also created an industrial classification system including four industries. This first industry includes agriculture, forestry, animal husbandry, fishery, and mining. The second industry includes manufacturing, electric power, production and supply industry of gas and water, construction industry. The third industry includes transportation, warehousing and postal service, information transmission, computer services and software, wholesale and retail trade, 
accommodation and catering industry, the financial sector, real estate, lease and business services, scientific research, technical service and geological prospecting industry, water conservancy, environment and public facilities management, residents service and other services, education, health, social security and culture, sports and entertainment, public administration and social organization, the international organization. The fourth industry is waste recycling industry.

7. Reducing, reusing and recycling the $3 R$ principle constitutes the basic theoretical framework of the circular economy. The $3 R$ principle constitutes an organic whole. In this whole, the reducing principle is the basis and premise, the overriding principle in this organism. First, the production and consumption have to change using the raw materials polluting the environment to using the renewable and recyclable materials as much as possible. Second, the producer shall produce the packaging materials, containers and other productions which can meet the consumer's demand, directly extension or recycling to reduce the production of waste. Through the application of the principles of reusing and recycling, the reducing principle can be deepened.

8. The basic elements of the system of the circular economy includes industrial elements, a complete industrial cycling chain which includes producer, consumer, and decomposer industries, internal supporting elements including the technical elements, policy elements, social elements and economic factors, external environmental elements including the external natural ecological environment and external environment inputting and outputting to the social and economic systems.

9. Other conclusions due to the circular economy system model framework.

(1) Recycling is conducive to the overall economic and social development.

(2) The factors of production and the waste for recycling should achieve a balanced growth in order to effectively improve the total utility. Otherwise, the low value of an investment will restrict the overall output. 
10. Suggestions and advice for government of Shanghai.

(1) Government should have a rational planning of eco-city, according to the construction of ecological city, and actively adjust the industrial policy, relying on market mechanisms foster the core industries of circular economy and build eco-city cycling industrial chain, to expand the scope of radiation circular economy, accelerate the process of building ecological society.

(2) An effective and simple communication platform is needed for the government. Whatever it is city government or district government, they are the intermediate institutes of information. The establishment of clean production and use of renewable resources and related technology supply and demand information network, and the establishment of material, energy and water, integrated software and technology integration method library are important. The government should and must establish a large-scale integrated information platform for the recycling economy.

(3) Enterprises should learn or imitate the sustainable developing mode of Baosteel, and meanwhile using their own advantages to improve the cycle in small, middle and large framework. Baosteel's resource regeneration business has achieved new progresses in 2012. Currently the two major categories of resource regeneration products which have formed mass production capabilities realized annual sales revenue of RMB 2.3 billion. Among such, new building material business has developed seven product lines, including slag micro powder and slag composite powder. New magnetic material business has developed three product lines, including lithium iron phosphate battery anode material. The annual sales revenue of Baosteel Magnetic has reached RMB 510 million. 


\section{Reference}

Abdel-Rahman, H. M. (1996). When do cities specialize in production? Regional Science and Urban Economics, 26(1), 1-22.

Allenby, B. R. (1994). The greening of industrial ecosystems: National Academies Press.

Amir, S. (1995). Welfare maximization in economic theory: Another viewpoint. Structural Change and Economic Dynamics, 6(3), 359-376.

Ayres, R. U., \& Schmidt-Bleek, F. (1995). Eco-restructuring: the transition to an ecologically sustainable economy: INSEAD.

Bailey, R., Bras, B., \& Allen, J. K. (2008). Measuring material cycling in industrial systems. Resources, Conservation and Recycling, 52(4), 643-652.

Bhuie, A., Ogunseitan, O., Saphores, J.-D., \& Shapiro, A. (2004). Environmental and economic trade-offs in consumer electronic products recycling: a case study of cell phones and computers. Paper presented at the Electronics and the Environment, 2004. Conference Record. 2004 IEEE International Symposium on.

Blume, V., \& Haasis, H.-D. (2004). Knowledge and decision support management in the circular flow economy. Paper presented at the Photonics Technologies for Robotics, Automation, and Manufacturing.

Boenker, T., Eckerth, G., \& Schmidt, G. (1998). Recycling economy as operator centre [Betreiberzentrum Kreislaufwirtschaft]. ZWF, 93(9), 403-406. 
Cao, H., Bucea, L., Ray, A., Yozghatlian, S., Kendi, T., Doyle, F., \& Commoner, B. (1997). The relation between industrial and ecological systems. Journal of cleaner production, 5(1), 125-129.

Chen, R. W., Navin-Chandra, D., \& Prinz, F. B. (1993). Product design for recyclability: a cost benefit analysis model and its application. Paper presented at the Electronics and the Environment, 1993., Proceedings of the 1993 IEEE International Symposium on.

Del Rio-Soto, R. (2002). A Strategic Environmental Management System (SEMS): Innovation—Both Entrepreneurial and Technological—Is the Key. Strategic planning for energy and the environment, 21(3), 8-30.

Di Vita, G. (1997). Macroeconomic effects of the recycling of waste derived from imported non-renewable raw materials. Resources Policy, 23(4), 179-186.

Diwekar, U., Small, M. J., \& Publif, E. S. (1998). Industrial Ecology and process optimization. Journal of Industrial Ecology, 2(3), 11-14.

Dobbs, I. M. (1991). Litter and waste management: Disposal taxes versus user charges. Canadian Journal of Economics, 221-227.

Fullerton, D., \& Kinnaman, T. C. (1995). Garbage, recycling, and illicit burning or dumping. Journal of Environmental Economics and Management, 29, 78-91.

GÖTTSCHING, L. (1996). The German recycling scene and the influence of legislation. Paper technology, 37(1), 47-51.

Hallberg, B., Aquilonius, K., Lechon, Y., Cabal, H., Saez, R., Schneider, T., . . . Korhonen, R. 66 
(2003). External costs of material recycling strategies for fusion power plants. Fusion Engineering and Design, 69(1), 699-703.

Halog, A., Schultmann, F., \& Rentz, O. (2001). Using quality function deployment for technique selection for optimum environmental performance improvement. Journal of cleaner production, 9(5), 387-394.

Hannon, B. (1991). Accounting in ecological systems. Ecological economics. The science and management of sustainability (R. Costanza, ed.). New York: Columbia University Press, 234-252.

Hill, B. S. (1993). Industry's integration of environmental product design. Paper presented at the Electronics and the Environment, 1993., Proceedings of the 1993 IEEE International Symposium on.

Hinderink, A., Kerkhof, F., Lie, A., De Swaan Arons, J., \& Van Der Kooi, H. (1996). Exergy analysis with a flowsheeting simulator-I. Theory; calculating exergies of material streams. Chemical Engineering Science, 51(20), 4693-4700.

Huisman, J., Boks, C., \& Stevels, A. (2000). Environmentally weighted recycling quotes-better justifiable and environmentally more correct. Paper presented at the Electronics and the Environment, 2000. ISEE 2000. Proceedings of the 2000 IEEE International Symposium on.

Huppes, G., van der Voet, E., \& Huele, R. (1997). Degrees of Immobilization: a Matter of Time. Paper presented at the Regional and National Material Flow Accounting,'From Paradigm to Practice of Sustainability'. Proceedings of the 1st ConAccount Workshop. 
Illge, L., \& Schwarze, R. (2009). A matter of opinion-How ecological and neoclassical environmental economists and think about sustainability and economics. Ecological Economics, 68(3), 594-604.

Jeng, J.-J., Chang, H., \& Chung, J.-Y. (2003). A policy framework for Business Activity Management. Paper presented at the E-Commerce, 2003. CEC 2003. IEEE International Conference on.

Kleineidam, U., Lambert, A., Blansjaar, J., Kok, J., \& Van Heijningen, R. (2000). Optimising product recycling chains by control theory. International Journal of Production Economics, 66(2), 185-195.

Leach, M. A., Bauen, A., \& Lucas, N. J. (1997). A systems approach to materials flow in sustainable cities: a case study of paper. Journal of Environmental Planning and Management, 40(6), 705-724.

Leu, H.-G., \& H Lin, S. (1998). Cost-benefit analysis of resource material recycling. Resources, Conservation and Recycling, 23(3), 183-192.

Lu, Q., Christina, V., Stuart, J., \& Rich, T. (2000). A practical framework for the reverse supply chain. Paper presented at the Electronics and the Environment, 2000. ISEE 2000. Proceedings of the 2000 IEEE International Symposium on.

Masui, T., Morita, T., \& Kyogoku, J. (2000). Analysis of recycling activities using multi-sectoral economic model with material flow. European Journal of Operational Research, 122(2), 405-415.

McLaren, J., Parkinson, S., \& Jackson, T. (2000). Modelling material cascades-frameworks for 68 
the environmental assessment of recycling systems. Resources, Conservation and Recycling, 31(1), 83-104.

Mellor, W., Wright, E., Clift, R., Azapagic, A., \& Stevens, G. (2002). A mathematical model and decision-support framework for material recovery, recycling and cascaded use. Chemical Engineering Science, 57(22), 4697-4713.

Moriguchi, Y. (2001). Material flow accounting as a tool for industrial ecology. Paper presented at the Environmentally Conscious Design and Inverse Manufacturing, 2001. Proceedings EcoDesign 2001: Second International Symposium on.

Nakajima, N. (2000). A Vision of Industrial Ecology: state-of-the-art practices for a circular and service-based economy. Bulletin of Science, Technology \& Society, 20(1), 54-69.

Nakamura, S. (1999). An interindustry approach to analyzing economic and environmental effects of the recycling of waste. Ecological Economics, 28(1), 133-145.

Perrin, D., \& Barton, J. (2001). Issues associated with transforming household attitudes and opinions into materials recovery: a review of two kerbside recycling schemes. Resources, Conservation and Recycling, 33(1), 61-74.

Perrings, C. (1998). Resilience in the dynamics of economy-environment systems. Environmental and Resource Economics, 11(3), 503-520.

Pistikopoulos, E., Stefanis, S., \& Livingston, A. (1994). A methodology for minimum environmental impact analysis. Paper presented at the AIChE Symposium Series. 
Potts Carr, A. J. (1998). Choctaw Eco-Industrial Park: an ecological approach to industrial land-use planning and design. Landscape and Urban Planning, 42(2), 239-257.

Rasmussen, R. (1997). The industrial symbiosis in Kalundborg and the symbiosis institute. Paper presented at the Proceedings of 1st European conference on industrial ecology. Barcelona, Spain.

Rees, W. E. (1992). Ecological footprints and appropriated carrying capacity: what urban economics leaves out. Environment and urbanization, 4(2), 121-130.

Ruth, M. (1995). Thermodynamic constraints on optimal depletion of copper and aluminum in the United States: a dynamic model of substitution and technical change. Ecological Economics, 15(3), 197-213.

Ruth, M., \& Harrington Jr, T. (1997). Dynamics of material and energy use in US pulp and paper manufacturing. Journal of Industrial Ecology, 1(3), 147-168.

Sage, A. P. (1997). Systems engineering and management for industrial ecology and sustainable development. Paper presented at the Systems, Man, and Cybernetics, 1997. Computational Cybernetics and Simulation., 1997 IEEE International Conference on.

Schlarb, M. (2001). Eco-industrial development: a strategy for building sustainable communities. Economic Development Administration, Washington, DC.

Schubert, H., \& Ziegahn, K.-F. (1995). Environment friendly economy by closed loops. Paper presented at the Institute of Environmental Sciences and Technology. Annual Technical Meeting. Proceedings. 
Schwarz, E. J., \& Steininger, K. W. (1997). Implementing nature's lesson: the industrial recycling network enhancing regional development. Journal of cleaner production, 5(1), 47-56.

Shu-Yang, F., Freedman, B., \& Cote, R. (2004). Principles and practice of ecological design. Environmental Reviews, 12(2), 97-112.

Stevels, A. (2002). Green Supply Chain Management much more than questionnaires and ISO 14.001. Paper presented at the Electronics and the Environment, 2002 IEEE International Symposium on.

Strebel, H. (2003). Industrial recycling networks as an entrance into circular economy. Paper presented at the Programme and Conference Proceedings of the Summer Academy on Technology Studies.

Toxopeus, M., \& De Jong, G. (1999). Life cycle oriented designing. Paper presented at the Environmentally Conscious Design and Inverse Manufacturing, 1999. Proceedings. EcoDesign'99: First International Symposium On.

Tummala, R. L., \& Koenig, B. E. (1994). Models for life cycle assessment of manufactured products. Paper presented at the Electronics and the Environment, 1994. ISEE 1994. Proceedings., 1994 IEEE International Symposium on.

Wagner, L. A. (2002). Materials in the economy, material flows, scarcity, and the environment (Vol. 1221): Geological Survey (USGS).

Wallner, H. P. (1999). Towards sustainable development of industry: networking, complexity and eco-clusters. Journal of cleaner production, 7(1), 49-58. 
Washida, T. (1994). The oil saving efficiency of recycling technology for waste plastics. Journal of Applied Input-Output Analysis, 2(1), 38-53.

Washida, T. (1998). Material dissipative conditions and the impossibility of complete recycling. Structural Change and Economic Dynamics, 9(3), 271-288.

Wedekind, S., \& Haasis, H.-D. (2004). Integration of service providers into supply chain services and waste disposal transports. Paper presented at the Photonics Technologies for Robotics, Automation, and Manufacturing.

Yu, P.-H., Leu, H.-G., \& Lin, S. H. (1996). Analysis of a municipal recyclable material recycling program. Resources, Conservation and Recycling, 17(1), 47-56. 